\title{
Creating the environment for driver distraction: A thematic framework of
}

\section{sociotechnical factors}

Katie J. Parnell ${ }^{\mathrm{a}}{ }^{\mathrm{a}}$, Neville A. Stanton ${ }^{\mathrm{a}}$, and Katherine L. Plant ${ }^{\mathrm{a}}$

*Corresponding author

${ }^{a}$ Transportation Research Group, Faculty of Engineering and the Environment, Boldrewood Innovation Campus, University of Southampton, Burgess Road, Southampton, SO16 7QF, United Kingdom.

\section{Abstract}

As modern society becomes more reliant on technology, its use within the vehicle is becoming a concern for road safety due to both portable and built-in devices offering sources of distraction. While the effects of distracting technologies are well documented, little is known about the causal factors that lead to the drivers' engagement with technological devices. The relevance of the sociotechnical system within which the behaviour occurs requires further research. This paper presents two experiments, the first aims to assess the drivers self-reported decision to engage with technological tasks while driving and their reasoning for doing so with respect to the wider sociotechnical system. This utilised a semi-structured interview method, conducted with 30 drivers to initiate a discussion on their likelihood of engaging with 22 different tasks across 7 different road types. Inductive thematic analysis provided a hierarchical thematic framework that detailed the self-reported causal factors that influence the drivers' use of technology whilst driving. The second experiment assessed the relevance of the hierarchical framework to a model of distraction that was established from within the literature on the drivers use of distracting technologies while driving. The findings provide validation for some relationships studied in the literature, as well as providing insights into relationships that require further study. The role of the sociotechnical system in the engagement of distractions while driving is highlighted, with the causal factors reported by drivers suggesting the importance of considering the wider system within which the behaviour is occurring and how it may be creating the conditions for distraction to occur. This supports previous claims made within the literature based model. Recommendations are proposed that encourage a movement away from individual focused countermeasures towards systemic actors.

Key words: In-vehicle technology, Driver distraction, Qualitative methods, Sociotechnical systems.

\section{Introduction}

Technological developments are largely driven by industrial or commercial requirements which, Dorf (2001) claims, are harnessed by mankind to change or manipulate their environment. The driving environment has changed markedly through the implementation of technology over recent decades (Walker et al, 2001). This has had ramifications for the design and use of vehicles (Wierwille, 1993; Walker et al, 2001). Drivers now 
expect the design of the vehicle to include technological facilities that enable entertainment, navigation, communication, connectivity, efficiency and comfort while driving. Yet, there is a need to ensure that the implementation of such technologies does not adversely affect road safety (Lee et al, 2008; Young et al, 2011).

The distractive effects of hand-held phones have been evidenced, with adverse consequences to driver performance metrics, such as vehicle control (Tsimhoni et al, 2004), attention tunnelling (Reimer, 2009), and hazard detection (Summala et al, 1998) among others. Yet, despite being made aware of the risks posed by mobile phones while driving and legislation to ban their use across many countries, drivers continue to engage with them (Dingus et al, 2006; Lerner et al, 2008; Walsh et al, 2008; Zhou et al, 2012; Young \& Lenné, 2010; Metz et al, 2015; Tivesten \& Dozza, 2015). While previous research has informed on the adverse consequences of mobile phones, the contextual and motivational factors that lead to engagement in other technological tasks is under-researched (Young \& Regan, 2007; Young et al, 2008; Young \& Lenné, 2010; Tivesten \& Dozza, 2015; Horrey et al, 2017).

Some research has been conducted into the decisions that drivers make to engage with distractions in simulators (Metz et al, 2011; Schömig \& Metz, 2013), on test tracks (Horrey \& Lesch, 2009) and through the analysis of data derived from naturalistic studies (Metz et al, 2015; Tivesten \& Dozza, 2015). A challenge in the assessment of driver distraction research is the dichotomy between high levels of control and the naturalistic study of behaviour (Young et al, 2008), thus the benefits and limitations of these studies are inherent to the validity of the findings. While simulators offer control over external variables, such as road type and other road users, capturing realistic behaviour is compromised (Young et al, 2008). Yet, in naturalistic studies the focus of data collection is on the driver and their triggered engagement with secondary tasks as they allow very little control, and thus measurement of, the contextual factors that influence drivers' engagement with secondary tasks (Metz et al, 2015). The World Health Organisation (WHO) now acknowledges the sociotechnical system based approach which identifies driver behaviour, not as a product of the individual, but as a product of systemic elements such as the road layout, road design, vehicle design, and the context surrounding the driving task (WHO, 2004). Despite this, the application of systems based error management approaches have been largely ignored (Salmon et al, 2010). The causal error taxonomy suggested by Stanton and Salmon (2009) states five key elements within the sociotechnical system which influence the conditions that lead to error; the driver, the vehicle, road infrastructure, other road users and environmental conditions. Thus, it can be suggested that the cause of distraction related errors is not limited to the driver, instead it is influenced by a multitude of other systemic actors.

Reviewing distraction with the sociotechnical systems 'risk management framework' (RMF) developed by Rasmussen (1997) revealed the impact that hierarchical levels of the system have on the emergence of distraction. Actors were revealed from the international and national committees (Parnell et al, 2017a) who 
set the laws that are enforced by local governments and regulators that then feed down the framework to the manufacturers of devices and the interaction they have with the end user (Young \& Salmon, 2012; Parnell et al, 2017a). Rather than focusing on the drivers' decision to engage as the initiation of error, the systems approach gives an insight into the conditions through which the driver was permitted to engage with distracting technologies and how this behaviour influences the emergence of safety within the system as a whole. Yet, appropriate methods are required to assess the sociotechnical system (Young et al, 2013; Salmon et al, 2017).

In a first attempt to assess and model driver distraction from a sociotechnical systems approach, Parnell et al (2016) developed the PARRC (Priority, Adapt, Resource, Regulate, Conflict) model of distraction, the first model of the behaviour to account for the contribution of systemic factors. This encompasses five key mechanisms through which in-vehicle technology may lead to distraction across the sociotechnical system, including 'goal priority', 'adapt to demand', 'resource constraints', 'behavioural regulation' and 'goal conflict' (Parnell et al, 2016). The PARRC model was developed through grounded theory methodology which determined the key factors involved in the emergence of distraction as evolved from the literature. The interconnections made between these mechanisms were shown to influence how distraction related behaviour emerged from the system, as well as the relevance of other systemic actors on the mechanisms. Readers are directed to Parnell et al (2016) for further information. Application of the PARRC model mechanisms to an Accimap analysis suggested how actors in the system may be preventing the emergence of distraction or conversely leaving the system open to distraction (Parnell et al, 2017a). This highlighted the role of legislation, developed through international and national committees that is then enforced through national laws, that targets hand-held mobile phone use but is more ambiguous on the use of other technologies. The ambiguity in legislation was shown to have led to the advancement of technologies and their implementation within the vehicle, despite a lack of evidence to suggest them to be safer than handheld mobile phones (Parnell et al, 2017a). Yet, the mechanisms of the PARRC model were drawn from the literature using grounded theory and therefore require validation through their application to other data sources, methods and/or investigators through the process of triangulation (Hignett, 2005; Rafferty et al, 2010).

This paper seeks to gain data from drivers on their self reported reasons for engaging with technology while driving. Questionnaires and online surveys have strived to gather responses on drivers' frequency of engaging with distractions and their views on the risks in doing so (e.g. McEvoy et al, 2006; Young \& Lenné, 2010; Walsh et al, 2008; Zhou et al, 2009; Zhou et al, 2012;). Yet, they are often prescriptive, posing closed questions that may limit the data to the agenda of the researcher ( $O^{\prime}$ Cathain \& Thomas, 2004). Instead, the causal factors that drivers deem to influence their decision to engage with distractions, and how this may result in distraction related events, is of interest (Young et al, 2008; Young \& Lenné, 2010; Lee, 2014). The first experiment within this paper sought to obtain the drivers self-reported reasons for engaging with 
technology while driving using a semi-structured interview method to engage drivers in open-ended discussions on why they may be more, or less, likely to engage with various types of technology while driving. The inductive thematic analysis that was applied during the data analysis aimed to develop factors that drivers themselves deem to influence their engagement with technological tasks. The second experiment aimed to assess how the causal factors derived from the drivers in the interview study related to the causal factors that were developed from the literature in the development of the PARRC model (Parnell et al, 2016). This model is used for its ability to assess the sociotechnical system surrounding the behaviour (Parnell et al, 2016;2017a). The findings seek to assist in the provision of countermeasures that target the source of the issue, rather than observing with hindsight the effects of distraction.

\section{Experiment 1}

\subsection{Aim}

This experiment aimed to understand the drivers self-reported reasons for engaging with technological devices while driving and the involvement of the sociotechnical in their decision-making process. Previous research has sought to capture the drivers' use of technologies using questionnaires and online surveys, yet this study aims to capture the drivers' subjective perspective in their own words. This will involve the use of semi-structured interviews to elicit discussions with drivers on their likelihood of engaging with different technological tasks across different road types.

\subsection{Method}

\subsubsection{Participants}

Drivers with experience of UK roads were specified as the road types included within the semi-structured interviews related to those comprising the UK roadway system (Walker et al, 2013). A total of 30 participants were recruited (15 females, 15 males), across three age categories (18-30, 31-49, 50-65), with five females and five males in each category. Participants were recruited under the requirement that they held a full UK driving license and had a minimum of 1-years experience driving on UK roads (mean years experience $=19.5$, $S D=13.08)$. They were also required to be frequent drivers, driving on a regular weekly basis in order for them to be exposed to situations where they may be inclined to engage with technology (mean hours spent driving a week $=9 \mathrm{hrs} 45 \mathrm{~min}, \mathrm{SD}=6 \mathrm{hrs} 20 \mathrm{mins})$. Participation was voluntary.

\subsubsection{Data collection}

To obtain the drivers own views on why they engage with technological devices while driving, semistructured interviews were conducted. Semi-structured interviews have been used effectively to investigate other aspects of driving behaviour (Simon \& Corbett, 2007; Gardner \& Abraham, 2007; Tonetto \& Desmet, 2016), but they have not been applied to study how driver distraction is viewed by drivers. Their application within this research allowed for open-ended questions that enabled drivers to generate concepts they 
deemed important to their use of technological devices whilst facilitating a structured data collection method that could be reliably applied across all interviewees. They also allowed the researcher to probe into interesting concepts as they arose (Cohen \& Crabtree, 2006).

The interviews were structured around a table that encouraged the driver to discuss their likelihood of engaging with a range of different technological tasks while driving across different UK road types in order to provide a discussion surrounding the situations and environments which may influence the use of different technological devices. Table 1 presents the list of technological tasks posed to participants in the interview. The tasks were drawn from the current literature investigating distraction from in-vehicle technology (e.g. Young \& Lenné, 2010; Neale et al, 2005; McEvoy et al, 2006; Harvey et al, 2011a), as well as reports from road safety organisations and police reports (RAC, 2016; Department for Transport, 2015a). The road types presented have been shown in previous research to influence drivers' situational awareness (Walker et al, 2013) and crash rates (Bayliss, 2009). They included motorways, major A/B roads, urban roads, rural roads, residential roads and junctions. Participants were presented with a road type classification sheet with definitions, images and contextual information relating to each of the road types for clarity.

Table 1. List of technologies/specific tasks that drivers were asked to rate their likelihood of engaging with.

\begin{tabular}{ll}
\hline Technology & Task \\
\hline Navigation system & Monitor route \\
& Enter destination \\
\hline \multirow{3}{*}{ Hands-free system } & Find number from address book \\
& Answer a call \\
& Talk to other \\
\hline & Change climate control \\
& Change song/radio station \\
& Adjust volume \\
In-vehicle system & Listen to music \\
& Verbally communicate with in-built system \\
\hline & Enter destination into navigation app \\
& Monitor navigation app \\
& Write/send a text \\
& Read a text \\
& Answer phone call \\
& Talk on the phone \\
& Enter/Find a number \\
& Change song/audio track \\
& Use voice assist features \\
& Take a photo \\
Use social media apps \\
Check your email
\end{tabular}

Participants were free to generate their own reasoning behind why they may or may not engage with a range of different technological tasks while driving across the road types. The researcher probed the participant to 
expand on their discussion points for clarity and further information where necessary. The same primary researcher conducted the interviews with all participants for consistency.

A pilot study was conducted to determine if the technological tasks were representative of those used by drivers and to establish agreement on the descriptions of the UK road types. This revealed an overlap in some of the technological tasks, such as searching for a point of interest and a destination in a sat-nav. It also revealed that when drivers discussed their behaviour at a junction they seemed to differ in their discussions surrounding the use of technology when stopped at a junction e.g. at traffic lights compared to driving through an intersection. Therefore, the junction road type was split in two to represent both driving through a junction and stopped at a junction.

The interviews lasted approximately 30minutes although this varied depending on the discussions engaged by the participant and the researcher (average $=34.21 \mathrm{mins}, \mathrm{SD}=14.07$ ). Interviews were audio recorded and transcribed. Due to the sensitive content, i.e. if they were likely to engage in an activity that may be considered illegal under UK laws such as using a mobile phone while driving, confidentiality was ensured to allow the participant to talk openly. The interview study was approved by the research institutes Ethical Research and Governance Organisation (ERGO reference: 24937).

\subsubsection{Data analysis}

Transcriptions of the interviews provided the data set from which to analyse and draw inferences on the causal factors that drivers reported to influence their decision to engage in the technological tasks while driving and determine the relationship of the factors to the wider sociotechnical system. Thematic analysis was used to organise, analyse and interpret key themes within the data (Braun \& Clarke, 2006). A theme was defined as "...something important about the data in relation to the research question, and represents some level of patterned response or meaning within the data set" (Braun \& Clarke, 2006; p10). The flexibility of the method is both an advantage, in facilitating adaptability across different approaches, and a limitation due to comments of limited rigour from unclear methodologies (Braun \& Clarke, 2006). Yet, Braun and Clarke (2006) comment that with clearly defined methods and commentary, thematic analysis can be a highly useful tool in drawing meaning from qualitative data. The methodology applied to the data set is therefore given in detail within this paper.

The thematic coding process was conducted in Nvivo11 software to add rigour to the qualitative research (Richards \& Richards, 1991; Welsh, 2002). It also assisted in reviewing the sub-themes (see Experiment 2), and allowed for queries to be run on the coded data to interrogate the codes after they were developed. 


\subsubsection{Inductive thematic coding}

The thematic analysis utilised a 'bottom-up' approach, whereby content was coded without a pre-existing framework, rather the framework developed through the analysis of the data (Boyatzis, 1998). Thus, the themes that developed were strongly linked to the source of the data (Patton, 1990). In contrast to deductive thematic analysis, which seeks to look at aspects of the data that relate to the research framework under investigation, inductive analysis provides a richer insight into the data set as a whole, using naturally occurring themes (Braun \& Clarke, 2006). It was not desirable to impose a framework on the drivers' verbalisations, but rather draw on the concepts that the participants deemed to be important. Braun and Clarke (2006) state that the clarity of the methodology used to develop thematic codes is essential to its validity, which led to the development of their own guidelines on conducting thematic coding. Their guidelines were followed and the process of applying them to the data collected from the interviews is shown in Figure 1. The same primary researcher that conducted the interviews also conducted the thematic analysis, as they were fully immersed in the data set.
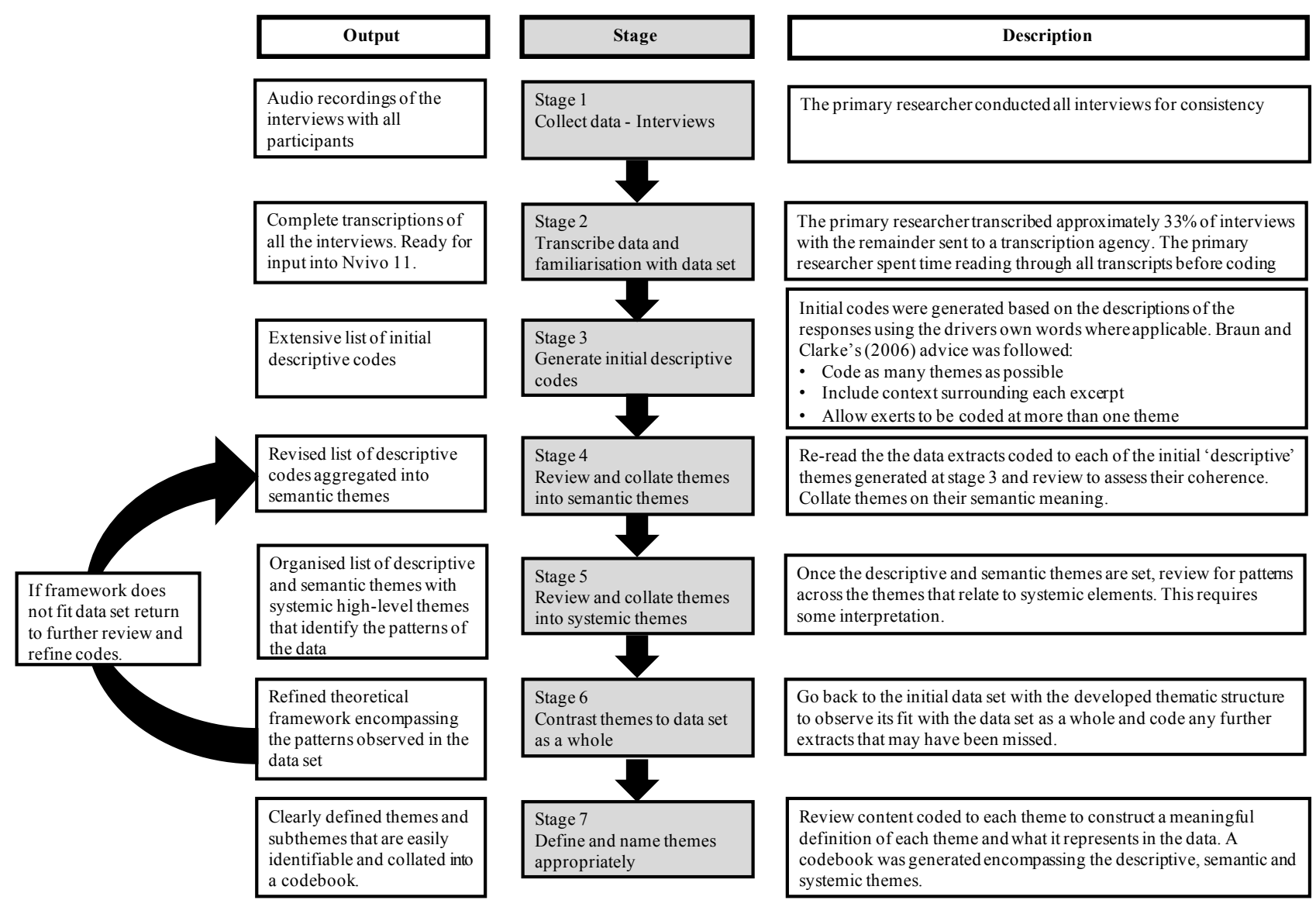

Figure 1. Stages of the inductive thematic analysis.

The iterative nature of inductive thematic analysis meant that the initial, descriptive, subthemes were coded as multiple individual concepts to draw as much information from the transcripts as possible (Stages 1-3, Figure 1). These were coded in the drivers own words, in-vivo, to stay true to the data (Richie \& Lewis, 2003) 
and allow an emerging framework to reflect the real-life experiences and thought processes of drivers (Tonetto \& Desmet, 2016). The multiple descriptive themes were then analysed, organised and refined into semantic themes (Stage 4). This required some interpretation and inductive theorising on the significance of concepts and their broader meaning (Patton, 1990).

\subsubsection{Inter-rater reliability test}

Allowing others, independent to the research project, to apply the code that has been applied to a data set is a useful way of assessing the reliability of the coding (Boyatzis, 1998). To test the coding framework $10 \%$ of the participants' transcripts were randomly chosen for inter-rater reliability testing. Two colleagues within the Human Factors research team were recruited to test inter-rater reliability. They were given the codebook, which presented the full thematic framework (see the Online Appendix), during a 45minute training briefing where the interview study was explained and the themes were described before they were asked to independently code the same $10 \%$ of the transcripts. The inter-raters were only required to code at the semantic level, while referencing the lower level descriptive themes to aid their coding. Nvivo11 software was used for the inter-rater coding with the researchers coding hidden. Percentage agreement was used to assess the reliability scores of the inter-raters in contrast to the researchers initial coding. This method is widely applied in inter-rater reliability studies (Boyatzis, 1998; Plant \& Stanton, 2013) and while there are still no established standards on the acceptable level of agreement between raters, Boyatzis (1998) deems $70 \%$ agreement as a necessary level of agreement. Both raters reached agreement percentages over this level (rater $1=81.24 \%$, rater $2=74.87 \%$ ). Thus indicating that the raters were able to use the framework to code the data at a level that was much higher than chance, attesting to the reliability of the researchers coding and the application of the thematic framework.

\subsection{Results}

Inductive thematic analysis resulted in the development of a hierarchical framework of themes that reflected the drivers' self-reported likelihood to engage in each of the technological tasks on each of the road types. An overview of the high level systemic and semantic themes is shown in Table 2. The full thematic framework, including the descriptive, semantic and systemic levels that were developed though the process (shown in Figure 1) is presented in the Online Appendix. 


\begin{tabular}{ll}
\hline \multicolumn{1}{c}{$\begin{array}{c}\text { Semantic } \\
\text { subthemes }\end{array}$} & \multicolumn{1}{c}{ Description } \\
Driver & References made by the driver including their mental/physiological state, experience, knowledge, skills, abilities and \\
& Negative: Reference to negative attitudes of the driver towards performing the task while driving \\
(D1) Attitude of driver & Positive: Reference to positive attitudes of the driver towards performing the task while driving \\
& Unnecessary: Reference to the driver perceiving the task to be unnecessary to perform while driving \\
(D2) Tendency & $\begin{array}{l}\text { Reference to the drivers stated tendency to perform the task in the past and/or the future as an indicator of their } \\
\text { likelihood to engage }\end{array}$ \\
(D3) View of self & $\begin{array}{l}\text { Reference to the drivers stated view of themselves and their own behavioural tendencies when stating their } \\
\text { likelihood to perform the task }\end{array}$
\end{tabular}

(D4) Influence of others Reference to other people and their influence on the driver and their likelihood of performing the task while driving

\section{Infrastructure \\ Perceptions of}

(I1) surrounding

environment

(12) Road Layout

(13) Illegality

(14) Task-road relationship

(15) Road related behaviour

\section{Task}

(T2) Interaction

(T3) Duration

(T4) Desirability

(T5) Engagement regulation
(T1) Complexity

Reft Reference to the context surrounding the road environment of a specific road type that is interpreted as an
influencing factor in the likelihood to perform the task in the specific road environment

Reference to features of the specific fixed road environment that influence the driver's likelihood to perform the task

Reference to the legislation on the use of the task while driving

Reference to the interaction between features of the road and the task that influence how the two may be compatible such that the likelihood of performing the task is influenced.

Reference to the actions and responses that are typical or required of the specific road type which influences the likelihood of performing the task on different roads. Reference to the details surrounding the specific task and engagement with it

(T6) Ability to complete Reference to features of the task which influence its ability to be completed in full while driving

Reference to physical features of the task that relate to the interaction required to perform the task while driving. This relates to the interface design, device location and driver required actions in order to engage with the task. Reference to the time and/or length of the task its use, performance or quality and options for alternative methods of completing the task.
Example Quote

aviour

"Because, I just think it is the worst thing in the world, I just wouldn't do it, it's terrible"

"I don't see any problem with it personally whatsoever"

"That's something - it's just something that can wait until when you get home I think"

"I have been known to do that"

'if I am stopped I generally am a little bit more naughty"

"the shame if you did something bad, that everyone would think you are so stupid"

\section{regulated conditions}

"for these roads and junctions, it would require a lot more concentration"

"because to me a motorway, once you are on it, it is all moving in the same direction generally"

"I usually hold it in a low position, so the police can't see"

"Yeah it would be stilted, I would probably make the person on the phone aware, say hang on a minute but I would probably sound not as engage"

"urban road I think is more busy as well so I think the more sort of decisions you've got to make"

"if you have to unlock the phone screen or whatever etc., it is not as simple - well it is quite distracting"

"It's only one button to press, so that's not an issue"

Reference to features of the task that influence how desirable it may be to perform while driving. This may include

"if it's a long text you might not read it"

"I don't really use my phone very much anyway so it's never been something that I have felt I have needed"

"I will always figure out what I'm going to listen to and set it going before I leave"

"because I've had the car for ages, I know where the switches are" 
(C1) Journey Context

Reference to circumstances that form the setting for a journey that may influence the likelihood to perform the task

"I I am in a strange city, I would be less likely to mess

around because I don't know where I am going"

Reference to circumstances that form the setting for the use of the task that influence the drivers' likelihood to engage with it.

"It's stuff when I actually feel like I need to send a

(C2) Task Context

message certain time and I'm running late for instance"

(C3) Road context

Reference to circumstances that form the setting surrounding the road in general (not related to specific

"I think it would be situational dependent, just how busy is infrastructure) that influence the likelihood to perform the task

it? I think"

Table 2 . The systems and semantic subthemes of the thematic framework. 
It is evident from the full table presented in the Appendix that there was an extensive list of reasons that drivers gave for engaging, or not engaging, with the technological tasks while driving. A total of 168 descriptive themes were iteratively generated and revised into 18 semantic thematic categories. The generation of these themes was a lengthy but in-depth process. Clustering these semantic themes into higher level systemic actors that contribute to the occurrence of the causal factors gave another level to the framework that readily demonstrates the contribution of the system within which driver distraction occurs. In line with previous individual focused approaches, the driver emerged as a key actor. The driver category suggests that the driver is influenced by their own attitudes (D1), perceptions of themselves (D3) and tendencies (D2) in their engagement with distractions while driving, as well as how they feel they may be viewed by others (D4). Yet, the development of the other categories suggests that they are also influenced by other systemic actors.

The role of infrastructure was also reported when responding to the different road types that were posed to the driver during the semi-structured interviews. Their perceptions of the road environment (I1) altered how likely they would be to engage due to the requirements of the driving task in these conditions e.g. increased concentration required at junctions or reduced perception of risk on motorways. Road layout across road types (12) was also widely discussed with the discussion of corners, road turnings, and road visibility stated as elements contributing to the decision to engage. Drivers also made connections between the road and their behaviour on it (I5), as well as between the task and its use in relation to the road (14). For example, the speed of particular roads or the availability of places to stop was discussed as contributing to their decision to engage while driving. Furthermore, the behaviour required in the driving task was also reported to influence their ability to engage in the different secondary tasks while driving, for example driving on a motorway was deemed to be easier by some drivers which motivated their engagement in more complex secondary tasks, than if they were in a more complex road environment. Illegality (13) was a theme that is also mentioned by drivers and is included in the road infrastructure theme, as it is in Stanton and Salmon (2009). Interestingly, the law was only one of the 168 other factors that drivers stated to influence their decision to engage. This highlights the potential for the development of other techniques to tackle the numerous other contributing factors, as a fear of the law was only a small contribution to the drivers selfreported causal factors.

The task itself generated discussion on how it influenced the likelihood of the driver to engage with it while driving. Notably, this included how long the task would take to complete (T3), the method through which they could interact with it (T2), the complexity of this interaction (T1), its desirability (T4), the ability for the task to be completed (T6) as well as how its onset may be regulated (T5). The task theme has the most semantic subthemes, highlighting the number of variables relating to the task that influence the drivers' engagement with it. It was evident that drivers were aware of the differing complexities and ways of interacting with the different technological tasks and how they could manage these while driving. The role 
of the manufacturer in facilitating engagement and the influence of developments in Human Machine Interface (HMI) design concepts was particularly evident throughout these discussions.

The other systemic category was the wider context within which drivers discussed their engagement with the technological tasks. They discussed the type of journey (C1) that they may be going on that may require them to engage with the task more. For example, the use of a sat-nav was more likely on a longer journey when they didn't know where they were going or a phone call may be more likely if they were commuting. The context of the task itself (C2) was also discussed with the importance of the task to their priorities referenced frequently. Notably, when discussing phone based tasks drivers reporting who was communicating with them and their perceived importance of the communication to greatly influence their engagement with the task.

\subsection{Discussion}

The development of the thematic framework in Table 2 is the first attempt to develop an extensive list of the drivers self-reported reasons for engaging with technological tasks. Previous efforts to assess the causal factors of driver error have suggested that the key factors relate to the following systemic elements: road infrastructure, the vehicle, the driver, other road users and environmental conditions (Stanton \& Salmon, 2009; Salmon et al, 2010). Thus far, the development of error taxonomies has been heavily theoretical, emerging from the aggregation of previous literature and accident reports (e.g. Stanton \& Salmon, 2009). The hierarchical levels of the framework that were inductively generated gave an insight into the higher level factors that are closely tied to the drivers own comments and discussions. The high-level factors suggest the importance of the driver, the road infrastructure, the task and the wider context on the drivers' decision to use the technological tasks while driving. Differences to the causal factors taxonomy presented by Stanton and Salmon, (2009) include a more specific focus on the task in the thematic framework rather than the vehicle as a whole. This is likely due to the design and aims of the study which required drivers to talk through their likelihood of engaging with a variety of different technological tasks. Had the participants been asked to drive or talk more about the interaction between completing the task while driving, more references to the vehicle may have emerged (Pedic \& Ezrakhovich, 1999). 'Other road users' is also absent from the highlevel themes of the thematic framework, but does appear within the infrastructure theme under the 'perceptions of surrounding environment' semantic subtheme (see the Online Appendix). This could suggest that the drivers' view of other road users is tightly linked to infrastructure and the surrounding environment when deciding to engage with technological tasks. Other research conducted in a naturalistic driving study has suggested that other vehicle in front of the driver do not influence drivers' decision to engage with technological tasks (Tivesten \& Dozza, 2015).

While there was an evident involvement of systemic actors that influenced engagement, the driver emerged as a key systemic theme due to the references that participants made to their attitudes, perceptions and 
views of engaging with the technological tasks. This compliments other research that utilised surveys to identify that drivers' intention to engage is strongly influenced by their attitude towards the behaviour and their perceived risk of the task (Welsh et al, 2008; Zhou et al, 2012). The voluntary aspect of distraction (Beanland et al, 2013) and its self-regulatory association (Tivesten \& Dozza, 2015) are inherent to the behaviour, yet this should not be studied independently to the wider context and system within the behaviour occurs (Young \& Salmon, 2015; Parnell et al, 2016).

The road infrastructure was discussed extensively leading to multiple themes within the framework. This compliments the research conducted in a naturalistic study by Tivesten and Dozza (2015) who found the drivers' ability to anticipate the road infrastructure, such as tight corners or straight roads, influences the drivers' engagement with distracting tasks. While they suggested that other road conditions did not influence the drivers' engagement as they could not be anticipated, the findings from this interview study suggest that road environment and the relationship between the task and the road is discussed as a causal factor in engagement and thus drivers can anticipate the effect is may have on their driving performance, within the interview setting. Other themes in the framework have also been suggested in the literature such as task context (Lerner et al, 2008), task capabilities (Zhou et al, 2009), journey context and the influence of others (Tivesten \& Dozza, 2015). Yet, the aggregation of factors that were inductively generated from a sample of drivers is novel and has strong theoretical applications.

The extensive range of causal factors within the framework includes the contribution of legislation to the drivers' decision to engage, yet there are a host of other contributing factors that suggest the potential for other measures through which to tackle the drivers' engagement with technologies that can lead to distraction related events. The PARRC model of distraction (Parnell et al, 2016) highlights the relevance of systemic actors to the causal factors that are attributed to driver distraction in the literature. The development of the thematic framework in Experiment 1 offers the possibility to contrast the causal factors that drivers report in the interview study to those that are reported in the literature. Furthermore, this offers the opportunity to determine the further avenues for distraction mitigation, as the PARRC model has sought to achieve in the past (Parnell et al, 2016;17). This is explored within Experiment 2.

\section{Experiment 2}

\subsection{Aim}

The inductive thematic analysis conducted in Experiment 1 allowed the causal factors that influence the drivers' likelihood of engaging with technologies to be directly linked to the drivers' discussions. The PARRC model of distraction sought causal factors directly from the literature using grounded theory methodology (Parnell et al, 2016). Yet, like the thematic framework developed in Experiment 1, it highlights the involvement of the wider sociotechnical system in the development of distraction. The aim of Experiment 2 will be to determine the relation of the drivers reports to the claims made in the literature by applying the 
thematic framework in Table 2 to the PARRC model of distraction developed in Parnell et al (2016). This will seek to assess the validation of the PARRC model through triangulation with its application to alternative data sources (Hignett, 2005). It will also assess if there are concepts that are reported by the drivers that have not been studied in the literature. It therefore seeks to promote future research as well as providing sociotechnical systems recommendations to the mitigation of distraction, as has been achieved with previous applications of the PARRC model (Parnell et al, 2016;2017b).

\subsection{Method}

The PARRC model of distraction (Parnell et al, 2016) was reviewed to assess how the literature-driven mechanisms relate to causal factors stated by drivers. The process through which this was achieved is detailed in Figure 2.

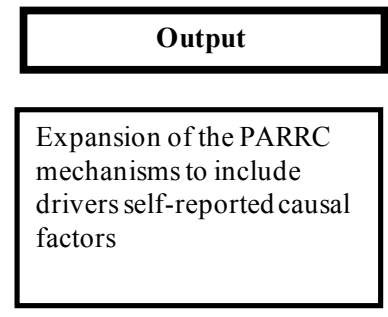

Frequency counts on the number of references in the interview transcripts that make connections between mechanisms of the PARRC model.

An understanding of what the interconnections of the PARRC model relate to in the drivers discussion.

A version of the PARRC model developed from the literature on driver distraction from technology and a version of a PARRC model developed from the drivers self reports in the interview.

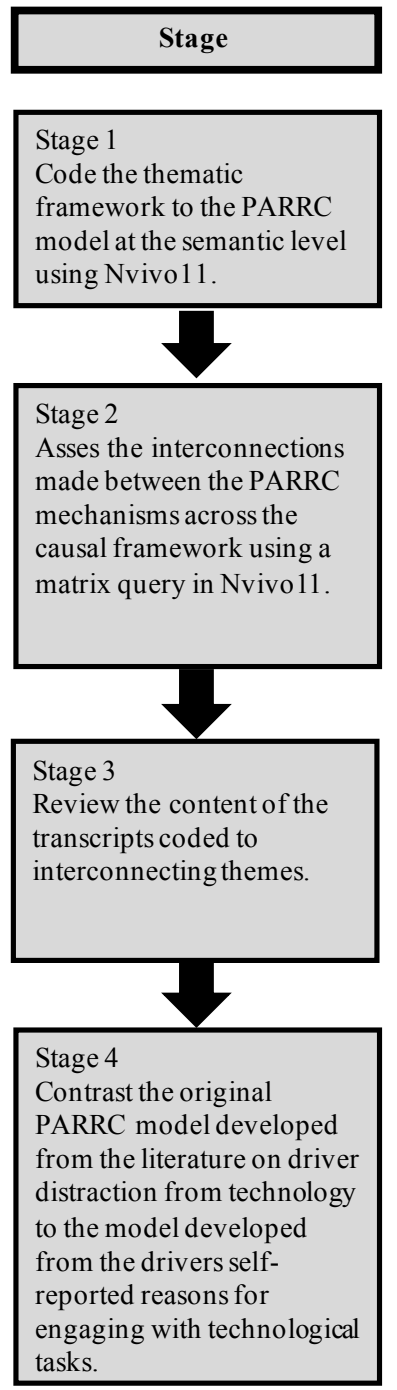

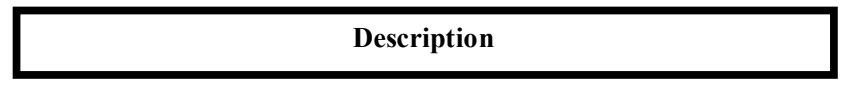

The semantic themes developed from the thematic coding of the interview transcripts were coded to the key mechanisms of the PARRC model; 'Goal priority', 'Adapt to demand', 'Resource constraints', 'Behavioural regulation' and 'Goal priority'. This was conducted with the discussion of subject matter experts.

Coding of the transcripts to the PARRC model mechanisms with the semantic themes in Nvivo 11 allowed a matrix query to be run in the software to calculate the number of references to co-occurring PARRC mechanisms. The frequency of connections made between the mechanisms can be used to infer the strength of the connections which can then be compared to the original PARRC model interconnections that were derived from observations in the literature.

From the matrix queries in Nvivo 11 the context of the transcripts that were coded to co-occurring PARRC mechanisms can be reviewed to understand what the interconnections mean to the driver themselves. These can then be contrasted to the interconnections that were identified by researchers in the literature that the PARRC model was grounded within.

The PARRC model was constructed from the interconnections that were referenced by the drivers, with the frequency of the interconnections visualised through the strength of the interconnections. This was then contrasted to the original PARRC model whose interconnecting mechanisms were constructed from the number references and significant relationships made between the mechanisms in the literature. Comparisons between the drivers stated behaviour and the behaviour studied in the literature.

Figure 2. Stages in the application of the thematic framework to the PARRC model of distraction.

The relationship of the semantic causal factors stated by drivers to the key factors identified from the literature in the PARRC model was reviewed through discussions with subject matter experts with over 40 years of Human Factors experience (Stage 1, Figure 2). The relationship of the semantic factors to systemic 
actors (stage 5 of the framework in Figure 1 ) meant that the contribution of the systemic actors to the causal mechanisms of the PARRC model could be identified. Furthermore, interconnections are important within systems models as sociotechnical systems emphasise emergence of safety from the complex interactions between systemic elements (Leveson, 2004). The interconnections in the original PARRC model were derived from empirically tested connections made in the literature as well as associations made by authors in relating concepts to one another. Connections between the causal factors reported by the drivers in the interview study in Experiment 1 were identified using a matrix query in Nvivo11 software that was used to code the data. Matrix queries allow the number of co-occurring coded themes to be quantified and highlighted, to determine the number and type of data excerpts that relate to co-occurring themes of interest. Stage 3 of the inductive thematic process (Figure 1), states the process for generating the initial descriptive codes within the data. This process requires excerpts to be coded at multiple themes (Braun \& Clarke, 2006), allowing cooccurring themes to be reviewed afterwards. The linking of the semantic subthemes to the PARRC model mechanisms in Figure 2, allowed the links between the subthemes representing each of the PARRC factors to be explored. The total number of interconnecting statements in the interviews between the PARRC mechanism subthemes was calculated. The connections could then be reviewed through the Nvivo11 software to further analyse the concepts that were coded to the interconnecting PARRC mechanisms (Stage 3, Figure 2). Comparisons could then be made between the original PARRC model, grounded in the literature, and the reconstructed PARRC model built from the drivers self-reported discussions on their reasons for engaging with technology while driving.

\subsection{Results}

Application of the semantic themes detailed in Table 2 to the PARRC factors and assessment of the interconnections referenced by the drivers led to the construction of the PARRC model developed from the drivers' self reported reasons for engaging with distractive technologies while driving (Figure 2, Stage 4). This is presented in Figure 3. Insights that were gained from the application of the PARRC model framework to the themes identified and inductively generated from the interviews are discussed. 


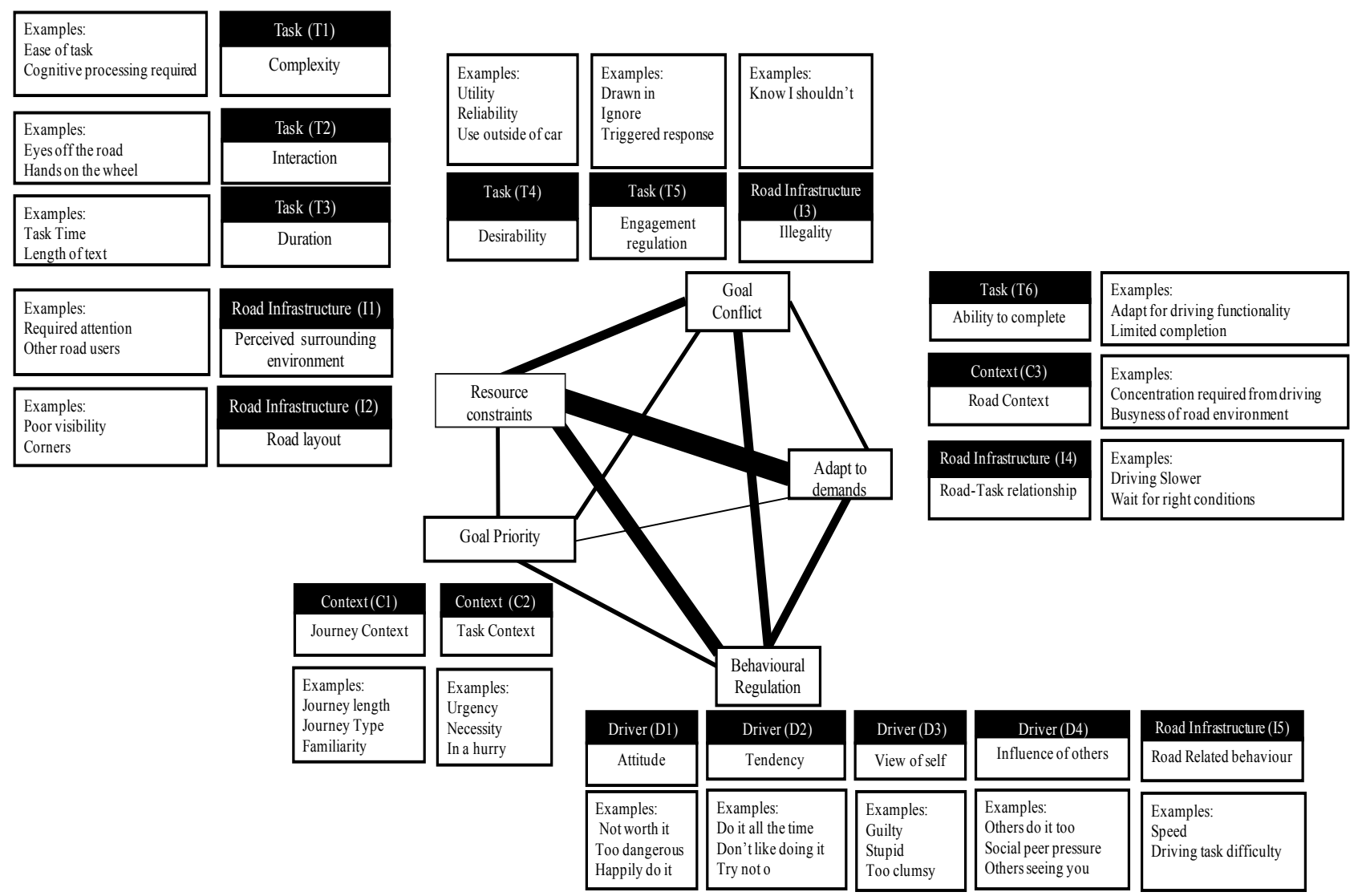

Figure 3. Application of the thematic framework, referenced in Table 2, to the PARRC model of distraction.

Each of the PARRC factors were found to be represented in the thematic framework developed from the drivers self-reported reasons for engaging with different technological tasks while driving. The relevance of these themes to the factors is discussed below.

Adapt to demands: Drivers supported the notion that they adapt both their behaviour in the driving task and the secondary task in line with increased mental and physical demand when discussing their likelihood of engaging with a technological task while driving. The semantic subtheme 'Road context' (C3) highlights the need to alter and adapt their driving behaviour in line with the changing demands of the road environment. The semantic subtheme 'Road-task relationship' (14) suggests that drivers also adapt their behaviour across different road types, such that they are aware of the different demands of different roads and alter their engagement with technology accordingly. In terms of the adaption of the technological task, the subtheme 'ability to complete' (T6) suggests that drivers adapt the functionality of the task, adjusting the completeness of it as illustrated in the example quote, in order to meet the demands of the driving task.

Behavioural regulation: The interviews provided information on the cognitive thought processes of the driver and their perceptions of their own behaviour relative to the surrounding environment. It has shown that the drivers 'attitude'(D1), 'tendencies' (D2), 'view of self' (D3), and the 'influence of others' (D4) are key factors that relate to the regulation of their behaviour with respect to engaging in technology whilst 
driving. Furthermore, as is demonstrated in the example quote (Table 2, 14), the behaviour of the driver is also shown to be regulated by the road infrastructure within the task-road relationship theme (14), with drivers discussing how they regulate their behaviour in relation to the road environment and attainment of the driving goal, which is altered across road types.

Goal conflict: Drivers discussed the limitations of responding to co-occurring driving and technological task goals with respect to the features of the technological tasks (T4 \& T5) and their knowledge on the laws (I3) which state the conflicting goals should not be achieved in unison (i.e. driving while using a hand-held phone under UK law). Features of the technological task which relate to its potential to conflict with the driving task were 'desirability' (T4) and 'engagement regulation' (T5). Technologies within the vehicle have developed over time to provide novel interactions and functionalities to the driver that were not previously available. This makes them desirable to would-be users (Walker et al, 2001) and therefore places them in conflict for attention with the main driving task. Drivers discuss the utility (T4) of the technologies and how this relates to their use while driving, as illustrated in the example quote (Table 2, T4). They also discuss the features of the task that determine how able they are to regulate the onset of the task (T5) and the arising conflict this may have with the driving task. For example, many drivers commented on the triggered response that occurred when they receive a text while driving, e.g. "'Reading a text', you see I would read a text just because of the nature of the fact that it flashes up on your phone." [Participant: 7, Task: Read text on mobile phone]. This suggests that drivers did not always wish to engage in the task but the design of the device allowed it to compete for the drivers' attention, diverting it away from the driving task.

Goal priority: The prioritisation of the goals was found to be influenced by the context and circumstance which surround the interaction, not just the road infrastructure but the specific circumstances that may, or may not, lead to interaction with technology. The journey type and/or length (C1) influenced the requirement to engage. For example, longer journeys may lead to more interactions with the music system. The familiarity (C1) with the route was also suggested to alter confidence in prioritising the technological task. The circumstances surrounding the technological task were also important (C2), such as how important or urgent the task was, as highlighted in the example quote. The contextual factors suggest there are many situations in which engagement with technology is more or less likely to occur. These do not relate to road type or environment but specific moments and circumstances that cannot be foreseen and directly impact on driver's willingness to engage.

Resource constraints: The attentional resources of the driver were reported to be constrained by features of the task (T1-T3) and features of the road environment (I1-I2). The road types presented to the drivers led them into a discussion on the features of the road that influences their decision to engage with technology. Discussions on the road layout (I2) and their interpretation of the surrounding environment (I1) highlighted the drivers' awareness for the elements of the road environment which may limit their 
attention. Likewise, there was also an in-depth discussion on the characteristics of the technological tasks presented to drivers and how features such as its 'complexity'(T1), method of 'interaction' (T2), and 'duration'(T3) influenced the attention that it required. In some cases, such as the example quote, the perceived resources required to interact are minimal which increases the likelihood of engaging, whereas for other tasks the perceived resources are too great to complete the task while driving.

Interconnections: Just as the mechanisms of the PARRC model were founded in grounded theory methodology, the interconnections between them were identified from the empirically tested connections made in the literature (Parnell et al, 2016). The total number of interconnecting statements in the interviews between the PARRC mechanism subthemes is shown in Figure 4b. In line with stage 4 in the application of the PARRC model to the thematic framework in Figure 2, this is contrasted to the interconnections found during the grounded theory approach in the original development of the PARRC model (Figure 4a). The numbers on the interconnections in Figure 4 a relate to the number of studies empirically testing the relationship between the factors. The size of the connecting lines represents the number of connections made in both diagrams. The matrix coding of the interview data only states the frequency of co-occurring subthemes, not the direction of any relationship that may occur, so the connections are shown as lines rather than directional arrows in Figure 4b.

a)

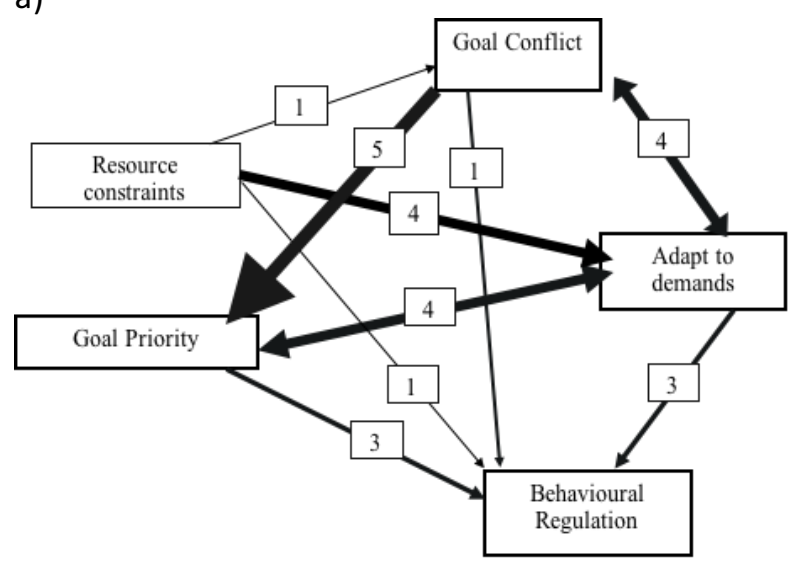

b)

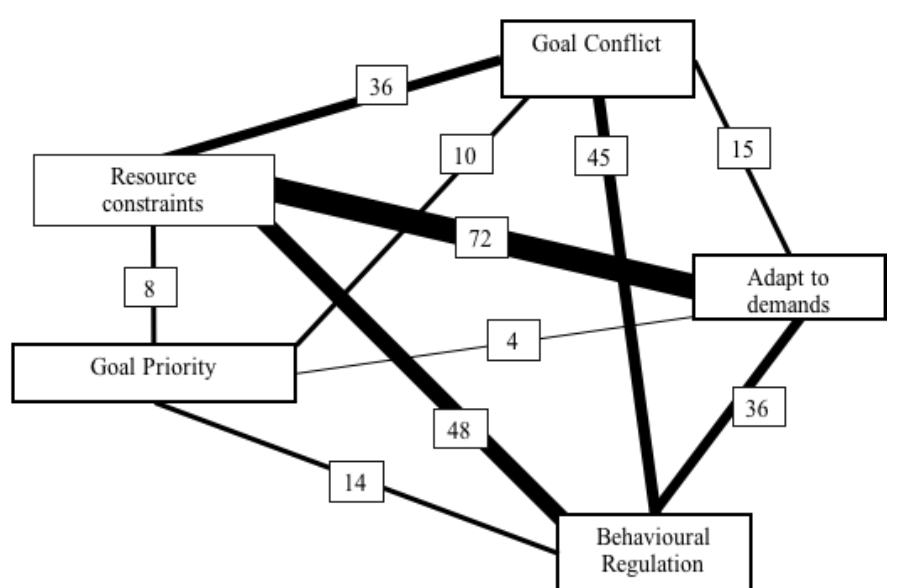

Figure 4. PARRC models created using a) empirically tested relationships in the literature (taken from Parnell et al, 2016) b) interview transcripts.

Figure 4 contrasts the interconnections between the PARRC factors in the original model (Figure 4a) and the one based on the drivers coded transcripts (Figure 4b). Aside from the quantities of total interconnections being higher in the interview driven connections (Figure 4b), which is likely to be due to rich data source of the interviews in contrast to the 33 studies identified in the literature review (Parnell et al, 2016), there are similarities in the configurations of the interconnections. This suggests support for the underlying literature that the PARRC model was grounded in, as the research is targeting concepts that are also generated to be important by drivers. 


\begin{tabular}{|c|c|c|c|}
\hline \multicolumn{2}{|c|}{ Connection } & Description & Quote \\
\hline Resource constraints & Goal Conflict & $\begin{array}{l}\text { Constrained resources means drivers cannot perform } \\
\text { two tasks at once so they are in conflict with each } \\
\text { other. }\end{array}$ & $\begin{array}{l}\text { Well, again it is just I would find it too distracting, I wouldn't be able to } \\
\text { drive and operate the software on my phone in order to enter the } \\
\text { destination, because I wouldn't be able to see properly! }\end{array}$ \\
\hline Resource constraints & Adapt to demands & Limited resources requires adaptation of behaviour. & $\begin{array}{l}\text { So the picture that you've got has lots of cars on the side of the road for } \\
\text { example and houses and l'd be thinking, "Ah a car is going to pull out in } \\
\text { front of me" or, "I'm going to get very close to a car" so therefore 100\% } \\
\text { needs to be on the road at that point. }\end{array}$ \\
\hline Resource constraints & Behavioural regulation & $\begin{array}{l}\text { Drivers must regulate behaviour in line with their } \\
\text { limited resources. }\end{array}$ & $\begin{array}{l}\text { Yes, I don't think that can be done in a safe amount of time. It would } \\
\text { have to be less than a second I think and even then, even that on a } \\
\text { motorway is risky. But I don't think I could do that in less than about } 20 \\
\text { seconds, even if I knew the postcode and everything. So I just wouldn't }\end{array}$ \\
\hline Goal Conflict & Goal Priority & Drivers prioritise to overcome conflict. & $\begin{array}{l}\text { So also depending on who is calling, so if for example work is calling I'Il } \\
\text { probably turn that off or some number that I don't know, whereas if it's } \\
\text { someone that I'm more likely to know or someone who's more likely to } \\
\text { tell me something important then I will answer more readily }\end{array}$ \\
\hline Goal Conflict & Adapt to demands & $\begin{array}{l}\text { Drivers can adapt to the demands of the conflicting } \\
\text { tasks. }\end{array}$ & $\begin{array}{l}\text { I would be highly likely to do this on a motorway, because I think it is } \\
\text { quite easy, again like using a phone I would do it staggered touch } \\
\text { something look up, touch something else, look up. }\end{array}$ \\
\hline Goal Conflict & Behavioural regulation & $\begin{array}{l}\text { The ability to regulate behaviour towards new tasks } \\
\text { that conflicts the driving task influences the conflict for } \\
\text { attention between the tasks. }\end{array}$ & $\begin{array}{l}\text { Just because it's more of a-for me, for some reason it's an automatic } \\
\text { response, so the phone flashes and you naturally just look over and then } \\
\text { you read the text. }\end{array}$ \\
\hline Adapt to demands & Goal Conflict & $\begin{array}{l}\text { Drivers adapt behaviour which can lead to further } \\
\text { conflict between goals. }\end{array}$ & $\begin{array}{l}\text { Yeah, into the car but I listen to play lists so it's never really... actually, } \\
\text { on the motorway it's finding a song, if I'm finding a song, searching on } \\
\text { Spotify whereas if I was on a rural road or a residential area, I'd just be } \\
\text { skipping a song. }\end{array}$ \\
\hline Adapt to demands & Goal Priority & $\begin{array}{l}\text { Drivers can adapt to demands by prioritising their } \\
\text { goals. }\end{array}$ & $\begin{array}{l}\text { The only time I might do it is at a junction, stopped; there's a chance I } \\
\text { might if I really need to make a call, but otherwise I wouldn't moving, } \\
\text { no. }\end{array}$ \\
\hline Adapt to demands & Behavioural regulation & $\begin{array}{l}\text { Drivers can regulate their behaviour to adapt to the } \\
\text { demands of the environment and the task. }\end{array}$ & $\begin{array}{l}\text { yeah, ok so changing climate controls I definitely would on the } \\
\text { motorway, as long as you are just cruising along }\end{array}$ \\
\hline Goal priority & Adapt to demands & $\begin{array}{l}\text { The prioritisation of goals requires adaption of the } \\
\text { primary and secondary tasks in line with current } \\
\text { demands. }\end{array}$ & $\begin{array}{l}\text { Rural road probably, it depends how rural, if it a really really tiny road I } \\
\text { probably don't answer it because it is quite nice to be able to hear the } \\
\text { road }\end{array}$ \\
\hline \multicolumn{4}{|c|}{ Additional connections } \\
\hline Behavioural Regulation & Goal Conflict & $\begin{array}{l}\text { The drivers attitude towards the task and stated } \\
\text { intention to engage with it while driving influence the } \\
\text { potential for the technological task to come into } \\
\text { conflict with the driving task }\end{array}$ & $\begin{array}{l}\text { No, never, never, never, never, never. Read a test? Honestly, I would } \\
\text { never do this stuff. }\end{array}$ \\
\hline Resource constraints & Goal Priority & $\begin{array}{l}\text { Drivers lend resources to the driving task to determine } \\
\text { its priority before deciding to engage with it. }\end{array}$ & $\begin{array}{l}\text { I would never open up a whole message, but I might glance down and } \\
\text { look at who it is from at least and what is written on it. }\end{array}$ \\
\hline
\end{tabular}


Table 3. Interconnections between the PARRC factors as drawn from the interview data.

The evidence for these connections found within the drivers self-reported likelihood of engaging with technologies provides support for the PARRC model, and the literature within which it was developed. Yet, some differences can be seen between the two models in Figure 4. These were assessed by looking towards the transcripts that were coded to the connecting themes in the matrix query and understanding how the drivers' reports may differ to those studied in the literature. They include the following:

- A reduction in the prominence of the connection between 'goal conflict' and 'goal priority'.

In the development of the original PARRC model connections, the literature was found to frequently consider the need to prioritise the goals of the driving task and the secondary task in order to resolve any goal conflict that may be occurring between the two (e.g. Dogan et al, 2011). Yet, the transcripts of the drivers verbalised thought process on their likelihood to engage in technological tasks suggests prioritisation of goals to be less of a concern.

- An increased prominence of the connection between 'resource constraints' and 'adapt to demands'.

Adaption of behaviour to manage resources was a well represented notion in the interview transcripts, with 72 statements connecting 'resource constraints' themes to adapt to demand themes. The connection was originally deemed to reflect the idea that adaption relates to the attentional resources that are available (Parnell et al, 2016). The PARRC model aligns with the theory that the attentional resources of drivers are limited, such that both the primary and secondary tasks must compete for available resources to facilitate their effective performance (Wickens, 2002). One way of ensuring that attentional resources are efficiently allocated across the primary and secondary task is through adaption (Noy et al, 1989; Cnossen et al, 2000). Figure $4 \mathrm{~b}$ and the example quote given in Table 3 suggest that drivers do report the adaption of their behaviour in order to facilitate their secondary task goal. It also suggests that this adaption to facilitate multiple goals is more important to drivers than the need to prioritise one goal over another.

- The addition of a connection between 'resource constraints' and 'goal priority', which was not found in the literature that the original PARRC model was developed from.

Another key difference between Figure $4 \mathrm{a}$ and $4 \mathrm{~b}$ is the addition of an extra connection between 'resource constraints' and 'goal priority', which was not found in the literature that the PARRC model was drawn from and is therefore absent in the original model (Figure 4a). Parnell et al (2016) reasoned that the absence of this connection could stem from a number of causes which relate to the other connections in the model. These include the prominent connection between 'goal priority', 'adapt to demands' and 'resource constraints', which prevents resources from constraining the prioritised goal, and facilitates adaption of behaviour in line with resource availability in order to prioritise one goal over another (Parnell et al, 2016). Yet, the findings from the interview data suggest that drivers do make a connection between 'resource constraints' and 'goal priority', although it is minimal. Table 3 gives an example statement of the connection made by the drivers and suggests the connection relates to drivers lending some 
attentional resources towards the task in order to determine if it requires prioritising. This is of interest as it suggests a concept that was not previously been considered in the literature from which the original PARRC model was conceived.

- An increased prominence of connection between 'goal conflict' and 'behavioural regulation'.

Figure 4a suggested the connection between 'behavioural regulation' and 'goal conflict' reflected the bottom-up process through which certain goals may result in triggered responses that realigns the conflicting goals (Parnell et al, 2016). The interview data presents a stronger connection between 'goal conflict' and 'behavioural regulation', in Figure $4 \mathrm{~b}$. A review of the coded transcripts connecting the mechanisms suggest it may reflect a connection in the opposite direction to the original PARRC model, going from 'behavioural regulation' to 'goal conflict'. The example quote from Table 3 highlights the influence that drivers' attitudes towards the technological tasks can have on their potential to conflict with the driving task. The driver in the example is adamant that they will never use the device while driving, stating they will turn it off so that it will not pose a conflict to their driving goal. This illustrates a reoccurring theme within the interview transcripts, many drivers held strong attitudes towards the use of technological tasks while driving stating that they would never ever attempt to engage in the task while driving.

\subsection{Discussion}

Experiment 2 has presented the application of the thematic framework that was developed in Experiment 1 to the PARRC model of distraction which presents the causal factors involved in driver distraction as stated in the literature. This has validated and extended the original PARRC model and the literature within which it is comprised. It has shown how the drivers' verbal reports relate to the study of the behaviour in the literature. Driver distraction can be a difficult behaviour to study in its natural environment due to other confounding factors and the ethical issues of exposing participants to distracting activities (Carsten et al, 2013). Therefore, capturing the drivers reported behaviour through open-ended discussions and establishing its relation to the existing literature provides much needed validation of the research.

The causal factors reported within the interviews and their association with the PARRC model factors supports other research from naturalistic driving studies. The notion of driver adaption is particularly evident with studies that have looked at drivers' engagement with secondary tasks, with drivers slowing down (Metz et al, 2015) and increasing headway (Tivesten \& Dozza, 2015) when engaging with secondary tasks. This supports the adaption of behaviour at the control level that has also been found in simulator studies (Schömig \& Metz, 2013; Cnossen et al, 2004). Yet, there was also a suggestion that drivers strategically plan their engagement with the technological tasks in advance. The notion that drivers' engagement with technology depends on journey type and road infrastructure have also been found in naturalistic driving studies (Tivesten \& Dozza, 2015).

There were, however, comments made by drivers that were not included in the development of the original PARRC model from the literature, which further highlights the importance of assessing the validation of models with the application to different sources (Hignett, 2005). This includes an adjustment within the structure of the model formed 
from the interview data which suggested less of a focus on prioritising goals directly and more reports of adapting their limited resource pool and attributing some resources to determining the priority of the secondary task before lending it further resources to carry out the task. This highlights the effect that tasks such as text messages have when they draw the drivers' attention towards the device and lead the driver to make a decision to prioritise the driving task or the text task. If the notification did not arise while the vehicle was in motion they would not be alerted to it and they would not need to re-establish their priorities.

Conversely, the connection between the 'behavioural regulation' and 'goal conflict' factors suggests that some drivers were able to control the goals that conflicted with the driving task due to their attitudes, perceptions and behaviour that regulated their engagement with the tasks while driving. This reflects others who suggest the role of driver attitude in their intention to engage with distractions while driving (Walsh et al, 2008; Zhou et al, 2009; Zhou et al, 2012). The suggestion that drivers' engagement with distractions are largely voluntary (Lee, 2014; Beanland et al, 2013), suggest that they do have an element of control over their behaviour but that they choose to become distracted. The development of the thematic framework and its application of the PARRC model aims to suggest that the drivers' decision to engage is not entirely straight forward and that banning the behaviour through legislation is not the only option. Instead there are numerous factors and actors to consider within the sociotechnical system, which are complexly interconnected in determine the emergence of distraction.

\section{General Discussion}

It is understood from previous research that the misuse of technological devices, such as sat-navs (Tsimhoni et al, 2004), music players (Young et al, 2012), hands-free phones (Horrey \& Wickens, 2006) mobile phones (McCartt et al, 2006) and wearable technologies (Sawyer et al, 2014) pose a threat to road safety. Whilst, research focuses on the adverse effects once the technology is engaged with by the driver, it fails to account for why the drivers choose to engage with the technology in the first place. An understanding of the key underlying causal factors that motivate drivers to engage with technologies is critical in providing recommendations and countermeasures to limit the adverse effects of driver distraction (Walsh et al, 2008; Atchley et al, 2011; Atchley et al, 2012; Zhou et al, 2009; Young \& Lenné, 2010). Furthermore, the relevance of systems based measures to countering driver distraction are required to improve the safety of the road transport system as a whole (Young \& Salmon, 2012; Salmon et al, 2012; Parnell et al, 2016).

The systemic level of the thematic framework suggests how actors outside of the drivers' control may be creating the conditions for distractions to be engaged with. Application of the thematic framework to the PARRC model in Experiment 2 suggested how the underlying themes relate to the PARRC factors, validating them with concepts derived from drivers reports of their own behaviour. Furthermore, exploration of the interconnections between PARRC factors has suggested some different structural connections within the model. As the original model reflected the empirically tested relationships in the literature, the difference in the interconnections found in this paper suggest potential gaps in the literature. The inductive analysis has provided factors that drivers themselves report to be important in their decision to engage with technological tasks while driving. This has supported the agenda of previous research that has applied behavioural intention literature to driver distraction (Welsh et al, 2008; Zhou et al 2009; Zhou et al, 2012). Yet, 
it has also highlighted the importance of the interacting elements in the road transport system in creating the conditions for drivers to make the decision to engage with technological secondary tasks while driving.

\subsection{Recommendations to practise}

The adverse implications of using specific technological tasks while driving are known (Horrey \& Wickens, 2006; Tsimhoni et al, 2004; McCartt et al, 2006; Young et al, 2012), yet the facilitating conditions are less acknowledged. By targeting the causal factors of distraction, countermeasures can be developed that focus on the underlying causes of the issue, rather than limiting its effects once engagement has been initiated. The thematic framework developed in Experiment 1 highlights the importance of the wider road transport sociotechnical system and its influence on technology use, including the driver, task, context and road infrastructure. This supports the importance of looking beyond individual focused methods of targeting driver distraction (Young \& Salmon, 2012; Salmon et al, 2012; Parnell et al, 2017).

To determine the importance of systemic actors to issues that are found within sociotechnical systems, the hierarchy of the system can be mapped using the RMF (Rasmussen,1997). This representation of the systems hierarchy is useful in determining how actors interact with each other (Rasmussen, 1997), which can then be used to assess the potential for incident as well as identifying future solutions (e.g. Young \& Salmon, 2012; Parnell et al, 2017). The location of key actors in the hierarchy can facilitate the provision of countermeasures that target elements higher up, to produce widespread change at lower levels (Branford et al, 2009). The adapted RMF hierarchy (Parnell et al, 2017) that includes an additional two high level themes, the national and international committees, alongside the original levels (the government, regulators, company and management; Rasmussen, 1997) was applied. The actors relevant to each of the systemic levels of the thematic framework were assessed to determine the actors across the hierarchical levels that could be targeted for future countermeasures. 


\begin{tabular}{|c|c|c|c|c|}
\hline $\begin{array}{l}\text { International } \\
\text { Committees }\end{array}$ & Driver & $\begin{array}{l}\text { Infrastructure } \\
\text { United Nations e.g. } \\
\text { The general assembly, } \\
\text { ECE Regulations }\end{array}$ & $\begin{array}{c}\text { Task } \\
\text { International } \\
\text { standardse.g. ISO, } \\
\text { SAE } \\
\text { World Health } \\
\text { Organisation (WHO) }\end{array}$ & Context \\
\hline $\begin{array}{l}\text { National } \\
\text { Committees }\end{array}$ & $\begin{array}{l}\text { Culture, Media \& Sport } \\
\text { Committee }\end{array}$ & $\begin{array}{l}\text { Transport Select } \\
\text { Committee }\end{array}$ & $\begin{array}{l}\text { Science \& Technology } \\
\text { Committee } \\
\text { British Standards } \\
\text { Organisation }\end{array}$ & \\
\hline Government & $\begin{array}{l}\text { Department for } \\
\text { Culture, Media \& Sport }\end{array}$ & $\begin{array}{l}\text { Department for } \\
\text { Transport }\end{array}$ & & \\
\hline Regulators & $\begin{array}{c}\text { Media } \\
\text { Road Safety Charities }\end{array}$ & $\begin{array}{l}\text { National Road } \\
\text { Safety Policy e.g. } \\
\text { The Highway Code, } \\
\text { Road Traffic Act }\end{array}$ & $\begin{array}{l}\text { UK HMI Design } \\
\text { Guidelines e.g. BSI code of } \\
\text { practise } \\
\text { UK Vehicle manufacturing/ } \\
\text { design standards }\end{array}$ & \\
\hline Industrialists & & & \begin{tabular}{|c|} 
Aftermarket/portable device \\
manufacturer \\
Telecommunication Association \\
Phone manufacturer \\
Vehicle manufacturers
\end{tabular} & Research centres \\
\hline $\begin{array}{l}\text { Resource } \\
\text { providers }\end{array}$ & $\begin{array}{l}\text { Driver education/training } \\
\text { providers }\end{array}$ & & \begin{tabular}{|} 
Aftermarket device designers \\
Driver assistance device \\
designers \\
Phone designers \\
In-vehicle interface designers
\end{tabular} & \\
\hline End User & $\begin{array}{c}\text { Passenger(s) } \\
\text { Other Road User(s) }\end{array}$ & & & Contacts on media devices \\
\hline $\begin{array}{l}\text { Equipment \& } \\
\text { Environment }\end{array}$ & & $\begin{array}{l}\text { Road type } \\
\text { Road features }\end{array}$ & $\begin{array}{l}\text { In-vehicle technology } \\
\text { (In-built or portable) }\end{array}$ & $\begin{array}{l}\text { Environmental } \\
\text { conditions }\end{array}$ \\
\hline
\end{tabular}

Figure 4. Systems actors across the hierarchy of the sociotechnical systems that are related to the four high-level systemic themes identified in the thematic analysis.

\subsubsection{Driver}

The drivers' attitude towards the use of the technology was found to play an important role in limiting its conflict with the driving goal. Elements of the system that impact on the driver and their attitudes towards technological devices appear across the hierarchy from those directly interacting with the driver, such as passengers or the presence of other road users who may be watching, to higher level actor such as educational providers, the media and road safety charities who can control attitudes in a more top down manner. A recent road safety campaign by THINK! in the UK with the tag line 'make the glove compartment the phone compartment', guides the driver away from placing the phone goal into conflict with the driving goal (THINK!, 2017). This would also prevent the driver from determining 
where the task lies in their goal priorities and how they may adapt their behaviour accordingly. Furthermore, the views we have on the use of technology while driving as a society are influenced by national committees who determine the importance of behaviour within national culture. The issue of road safety is a social responsibility that should be shared by the top level of the system (Larsson et al, 2010) and therefore the use of technologies while driving need to be portrayed as anti-social when it conflicts with the safe monitoring of the driving task.

\subsubsection{Infrastructure}

As an integral part of the transportation system, road infrastructure is regulated at the international, national and governmental levels with the aim to develop an efficient road transport system (e.g. Department for Transport, 2015b). The interaction of road type with technological engagement has been explored here to identify that drivers do consider the road environment when they decide to use technology while driving, as has also been identified in naturalistic driving studies (Tivesten \& Dozza, 2015). On motorways, descriptive themes such as 'just cruising' and 'consistent' road layouts suggest that drivers deem the driving task to be less demanding on these roads compared to rural roads where 'poor visibility' and 'corners' may increase demand in the secondary task. Yet, at the industrial and resource providers level there are no actors directly influencing which tasks are compatible with different road infrastructures (Salmon et al, 2012). Future research should determine if certain tasks and technologies are more compatible with certain road environments. For example, interacting with a sat-nav may be easier on a motorway but it has limited use here as there is generally more roadside information and the distance between junctions is greater than on rural or urban roads, which may be more demanding but hold a greater requirement to engage with the satnav to navigate through fast changing environments. Tivesten and Dozza (2015) also came to similar conclusions suggesting the potential for some road areas where phone use may be regulated, rather than banned.

\subsubsection{Task}

The technological task is associated with a number of systems elements from the very top of the hierarchy to the bottom. The design of technological tasks is influenced by a number of guidelines, standards and criteria that stem from international and national actors, which are then fed down to the individual manufacturers and developers. Yet, there is also a need to represent the views of the end user and apply iterative design procedures that allow for the evaluation of in-built systems usability with respect to the driver and the context of use (Harvey et al, 2011b). The drivers that were interviewed made numerous references to the task features, such as how it may take their eyes off the road or their hands off the wheel under the 'interaction' subtheme, as well as referencing the 'complexity' and 'duration' of the task. This suggests drivers had an understanding of the attentional requirements of the technological tasks. Design standards and guidelines have aimed to inform what is achievable while driving, yet they do not necessarily take into consideration the desire that drivers have to use the technology at the end user level. Indeed, other research presented in this journal suggests that different drivers need and desire different information under different contexts (Davidsson \& Alm, 2014). By facilitating the functioning of the technology in the vehicle, the temptation for the driver to engage will endure, this is particularly true of mobile phones (Nelson et al, 2009). The multi-functionality of phones provides extra temptation for the driver to engage with it while driving and this should be responded to by device developers by limiting functionality while driving. There were numerous comments relating 
to the notifications received on mobile phone when drivers received texts or phone calls which trigger a response from the driver. The presence of technologies with capabilities to trigger a response that takes the drivers attention away from the driving task, even momentarily, should be revised by device manufacturers as it forces the end user to assess their priorities which should predominately focus on the driving task and road safety (Lee et al, 2008). The manufacturer Apple has taken steps towards this with their recent phone update (ios11, released September 2017) that includes a 'do not disturb while driving' mode that can sense when the device is in a moving vehicle and, once prompted by the user, will turn off notifications (Apple, 2017). There is, therefore, the potential for new regulations that target the desires and engagement regulation of technology use to stem from the very top levels of the sociotechnical system and focus on the influences across the levels of the system, not just the driver.

\subsubsection{Context}

The framework highlighted the importance of circumstance in the drivers' decision to engage. There are many complexly interacting factors influencing the use of technology while driving that relate to the road environment, the driver and the task itself. The information that drivers require and desire under different contextual demands is likely to differ (Davidsson \& Alm, 2014; Tivesten \& Dozza, 2015). The effects of context occur in a predominantly bottom up fashion within the system hierarchy as they are determined by the interactions with the surrounding environmental conditions. Figure 5 shows the lack of high level actors on context within the sociotechnical system which is reflective of the limited control over the complexly integrated factors that comprise individual circumstances. Road conditions are hard to control as they are influenced by environmental conditions such as time of day, road type and weather conditions. Task conditions relating to the urgency or necessity to interact suggest that drivers assess their priorities as tasks and requirements arise. Yet, determining and setting priorities in advance, or predefining situations where engagement would be more or less necessary could look to control technology engagement at higher levels in the system. Research centres offering facilities to test different contextual factors through the use of driving simulators and highly controlled environments can offer promising insights into the role of context on driver engagement (e.g. Konstantopoulos et al, 2008) and future work should asses the complexly interacting conditions that influence drivers desire to engage.

\subsection{Evaluation and Future work}

The framework was developed from the self-reported behaviours of a sample of 30 participants, which is small in contrast to the number of participants that can be recruited from online surveys that facilitate far-reaching recruitment databases. However, the data obtained was much richer, with over 17 hours of audio recordings and transcribed data. Furthermore, the sample strived to include drivers of an equal range of age and genders to generate a framework based on a representative sample. While the research focused on UK drivers, the laws relating to technology use in the vehicle are similar across Europe, Australia, New Zealand, Japan and India who specifically ban the use of mobile phones. However, future work should seek to explore how the framework of causal factors may alter with individual and cultural differences, as this may influence the use of technology both inside and outside of the vehicle (e.g. McEvoy et al, 2007; Shiner et al, 2005; McEvoy et al, 2006; Young \& Lenné, 2010; Horberry et al, 2006). 
An advantage of the thematic framework is its grounding in the self-reported behaviours of drivers, such that the causal factors are directly informed by those who experience them. The use of the interview setting allowed the drivers to openly discuss all factors that they felt influenced their likelihood of engaging. While other studies have explored the drivers' willingness to engage with distractions in simulators (Metz et al, 2011; Schömig \& Metz, 2013) and in naturalistic driving settings (Metz et al, 2015; Tivesten \& Dozza, 2015) they have looked at the drivers' physical engagement with the task relative to the context of the road environment, rather than enabling the drivers to discuss their motivations to engage. The study conducted by Lerner et al (2008) facilitated drivers to discuss their willingness to engage with distractions within focus groups, yet this may have been effected by the social dynamics and biases when discussing behaviours that be undesirable (Smithson, 2000; Lajunen \& Summala, 2003). The drivers' discussions in Experiment 1 were conducted with confidentiality and anonymity which encouraged drivers to reveal their true views. This discussion also allowed for insights into the wider sociotechnical system and its involvement in the issue of driver distraction to be revealed, a concept that was not obtained by the objective measurements in simulator or naturalistic studies (e.g. Metz et al, 2011; Schömig \& Metz, 2013; Metz et al, 2015; Tivesten \& Dozza, 2015). While it is important to review the drivers' willingness to engage within the context that the behaviour arises, the open discussions with drivers, prompted with different road types and technological tasks, has uncovered a variety of factors that influence their willingness to engage that has not been explored previously. Furthermore, this has provided validation of previous research, as well as proposing the possibility of future explorations of the behaviour and ways to mitigate against it.

\section{Conclusions}

This paper has presented the development of a thematic framework of the causal factors that motivate drivers to engage with technology while driving. The use of semi-structured interviews enabled drivers to discuss their likelihood of engaging with a variety of technological tasks across common UK road types. The structure of the interviews allowed all participants to discuss the same tasks and road types while freely generating the key concepts that were important to their perceived likelihood of performing the task. Inductive thematic analysis facilitated the development of a hierarchical framework of causal factors that was driven from the driver own interpretations, rather than applying predefined theories. This has shown the influence of systemic actors on the causal factors influencing technology use while driving, highlighting how the road transport system may be creating the conditions for driver distraction to occur. This should encourage a movement away from individual focused countermeasures and towards the role of systemic actors, which has been highlighted through the application of the thematic framework to the interacting mechanisms of distraction from the PARRC model (Parnell et al, 2016). The thematic analysis has shown the relevance of the PARRC factors to the systemic and semantic themes that drivers report to influence their engagement with technological devices. This has supported previous literature in the field, whilst also suggesting additional concepts of interest. Assessment of the actors impacting on the systemic themes identified from the interviews across the hierarchy of the sociotechnical systems has highlighted future areas for research and countermeasure implementation. 


\section{Acknowledgements}

This research was funded by the Engineering and Physical Science Research Council (EPSRC) grant EP/G036896/1, under the Industry Doctoral Training Centre in Transport and the Environment.

\section{References}

Altman, D. G. (1990). Practical Statistics for Medical Research. CRC press.

Apple (2011). How to use the Do Not Disturb while Driving feature. https://support.apple.com/en-gb/HT208090

Atchley, P., Atwood, S., \& Boulton, A. (2011). The choice to text and drive in younger drivers: Behaviour may shape attitude. Accident Analysis \& Prevention, 43(1), 134-142.

Atchley, P., Hadlock, C., \& Lane, S. (2012). Stuck in the 70s: The role of social norms in distracted driving. Accident Analysis \& Prevention, 48, 279-284

Bayliss, D. (2009). Accident Trends by Road type. Motoring Towards 2050 - Roads and Reality Background Paper No.9. March. Royal Automobile Club Foundation. Bayliss, D. (2009). http://www.racfoundation.org/assets/rac_foundation/content/downloadables/roads\%20and\%20reality\%20\%20bayliss\%20-\%20accident\%20trends\%20by\%20road\%20type\%20-\%20160309\%20\%20background\%20paper\%209.pdf Accessed 01/08/2017.

Boyatzis, R. E. (1998). Transforming qualitative information: Thematic analysis and code development. Sage.

Branford, K., Hopkins, A., \& Naikar, N. (2009). Guidelines for AcciMap analysis. In Learning from High Reliability Organisations. CCH Australia Ltd.

Braun, V., \& Clarke, V. (2006). Using thematic analysis in psychology. Qualitative Research in Psychology, 3(2), 77-101

Carsten, O., Kircher, K., \& Jamson, S. (2013). Vehicle-based studies of driving in the real world: The hard truth? Accident Analysis \& Prevention, 58, 162-174.

Cnossen, F., Meijman, T., \& Rothengatter, T. (2004). Adaptive strategy changes as a function of task demands: a study of car drivers. Ergonomics, 47(2), 218-236.

Cohen D, Crabtree B. (2006) Qualitative Research Guidelines Project. July http://www.qualres.org/HomeSemi3629.html Accessed 22/04/2017.

Davidsson, S., \& Alm, H. (2014). Context adaptable driver information-Or, what do whom need and want when?. Applied Ergonomics, 45(4), 994-1002.

Department for Transport (2015a). Reported Road Casualties Great Britain: 2015. Annual Report.

https://www.gov.uk/government/uploads/system/uploads/attachment_data/file/568484/rrcgb-2015.pdf Accessed 28/04/2017.

Department for Transport (2015b). 2010 to 2015 Government Policy: Road network and traffic. May. The Stationary Office, London.

Dingus, T. A., Klauer, S. G., Neale, V. L., Petersen, A., Lee, S. E., Sudweeks, J. D., ... \& Bucher, C. (2006). The 100-car naturalistic driving study, Phase II-results of the 100-car field experiment (No. HS-810 593). Washington USA.

Dogan, E., Steg, L., \& Delhomme, P. (2011). The influence of multiple goals on driving behaviour: The case of safety, time saving, and fuel saving. Accident Analysis \& Prevention, 43(5), 1635-1643. 
Dorf, R. C. (2001). Technology, humans, and society: toward a sustainable world. Academic Press.

Gardner, B., \& Abraham, C. (2007). What drives car use? A grounded theory analysis of commuters' reasons for driving. Transportation Research Part F: Traffic Psychology and Behaviour, 10(3), 187-200.

Harvey, C., Stanton, N. A., Pickering, C. A., McDonald, M., \& Zheng, P. (2011a). To twist or poke? A method for identifying usability issues with the rotary controller and touch screen for control of in-vehicle information systems. Ergonomics, 54(7), 609-625.

Harvey, C., Stanton, N. A., Pickering, C. A., McDonald, M., \& Zheng, P. (2011b). A usability evaluation toolkit for invehicle information systems (IVISs). Applied Ergonomics, 42(4), 563-574.

Hignett, S. 2005. "Qualitative methodology in ergonomics". In Evaluation of human work, Edited by: Wilson, J. R. and Megaw, E. Taylor and Francis. London, UK.

Horberry, T., Anderson, J., Regan, M. A., Triggs, T. J., \& Brown, J. (2006). Driver distraction: The effects of concurrent in-vehicle tasks, road environment complexity and age on driving performance. Accident Analysis \& Prevention, 38(1), 185-191.

Horrey, W. J., \& Wickens, C. D. (2006). Examining the impact of cell phone conversations on driving using metaanalytic techniques. Human factors: The Journal of the Human Factors and Ergonomics Society, 48(1), 196-205.

Horrey, W. J., Lesch, M. F., Garabet, A., Simmons, L., \& Maikala, R. (2017). Distraction and task engagement: how interesting and boring information impact driving performance and subjective and physiological responses. Applied Ergonomics, 58, 342-348.

Jamson, A. H., Westerman, S. J., Hockey, G. R. J., \& Carsten, O. M. (2004). Speech-based e-mail and driver behaviour: Effects of an in-vehicle message system interface. Human Factors: The Journal of the Human Factors and Ergonomics Society, 46(4), 625-639.

Konstantopoulos, P., Chapman, P., \& Crundall, D. (2010). Driver's visual attention as a function of driving experience and visibility. Using a driving simulator to explore drivers' eye movements in day, night and rain driving. Accident Analysis \& Prevention, 42(3), 827-834.

Lajunen, T., \& Summala, H. (2003). Can we trust self-reports of driving? Effects of impression management on driver behaviour questionnaire responses. Transportation Research Part F: Traffic Psychology and Behaviour, 6(2), 97-107.

Larsson, P., Dekker, S.W., Tingvall, C., (2010). The need for a systems theory approach to road safety? Safety Science. 48 (9), 1167-1174

Lee, J.D., Young, K.L., Regan, M.A., (2008). Defining driver distraction. Driver Distraction: Theory, Effects and Mitigation, pp. 31-40. Boca Raton, FL: CRC Press.

Lerner, N., Singer, J., \& Huey, R. (2008). Driver strategies for engaging in distracting tasks using in-vehicle technologies (No. HS-810 919). National Highway Traffic Safety Administration.

Leveson, N.G., (2004). A new accident model for engineering safer systems. Safety Science. 42(4), 237-270.

Leveson, N.G., (2011). Applying systems thinking to analyse and learn from events. Safety Science 49(1), 55-64.

McCartt, A. T., Hellinga, L. A., \& Bratiman, K. A. (2006). Cell phones and driving: review of research. Traffic Injury Prevention, 7(2), 89-106.

McEvoy, S. P., Stevenson, M. R., \& Woodward, M. (2006). The impact of driver distraction on road safety: results from a representative survey in two Australian states. Injury Prevention, 12(4), 242-247. 
McEvoy, S. P., Stevenson, M. R., \& Woodward, M. (2007). The prevalence of, and factors associated with, serious crashes involving a distracting activity. Accident Analysis \& Prevention, 39(3), 475-482.

Metz, B., Schömig, N., \& Krüger, H. P. (2011). Attention during visual secondary tasks in driving: Adaptation to the demands of the driving task. Transportation Research Part F: Traffic Psychology and Behaviour, 14(5), 369-380.

Metz, B., Landau, A., \& Hargutt, V. (2015). Frequency and impact of hands-free telephoning while driving - Results from naturalistic driving data. Transportation Research Part F: Traffic Psychology and Behaviour, 29(0), 1-13.

Neale, V. L., Dingus, T. A., Klauer, S. G., Sudweeks, J., \& Goodman, M. (2005). An overview of the 100-car naturalistic study and findings. National Highway Traffic Safety Administration, (Paper 05-0400).

Nelson, E., Atchley, P., \& Little, T. D. (2009). The effects of perception of risk and importance of answering and initiating a cellular phone call while driving. Accident Analysis \& Prevention, 41(3), 438-444.

Noy, Y. I. (1989). Intelligent route guidance: will the new horse be as good as the old?. In Vehicle Navigation and Information Systems Conference, September. Toronto, Ontario, Canada (pp. 49-55). IEEE.

O'Cathain, A., \& Thomas, K. J. (2004). " Any other comments?" Open questions on questionnaires-a bane or a bonus to research? BMC Medical Research Methodology, 4(1), 25.

Parnell, K. J., Stanton, N. A., \& Plant, K. L. (2016). Exploring the mechanisms of distraction from in-vehicle technology: The development of the PARRC model. Safety Science, 87, 25-37.

Parnell, K. J., Stanton, N. A., \& Plant, K. L. (2017). What's the law got to do with it? Legislation regarding in-vehicle technology use and its impact on driver distraction. Accident Analysis \& Prevention, 100, 1-14.

Patton, M. Q. (1990). Qualitative evaluation and research methods. SAGE Publications, Inc.

Pedic, F., \& Ezrakhovich, A. (1999). A literature review: the content characteristics of effective VMS. Road \& Transport Research, 8(2), 3.

Plant, K. L., \& Stanton, N. A. (2013). What is on your mind? Using the perceptual cycle model and critical decision method to understand the decision-making process in the cockpit. Ergonomics, 56(8), 1232-1250.

RAC, (2016). RAC Report on Motoring 2016. The Road to the Future. https://www.rac.co.uk/pdfs/report-onmotoring/rac-report-on-motoring-2016-outline.pdf Accessed 28/04/2016.

Rafferty, L. A., Stanton, N. A., \& Walker, G. H. (2010). The famous five factors in teamwork: a case study of fratricide. Ergonomics, 53(10), 1187-1204.

Reimer, B. (2009). Impact of cognitive task complexity on drivers' visual tunnelling.

Transportation Research Record: Journal of the Transportation Research Board, (2138), 13-19.

Richards, L. \& Richards, T. (1991). The Transformation of Qualitative Method: Computational Paradigms and Research Processes. In Nigel G. Fielding, \& Raymond M. Lee (Eds.), Using Computers in Qualitative Research (pp.38-53). London: Sage.

Ritchie J., Lewis J. (2003) Qualitative Research Practice. Sage Publications, London

Salmon, P. M., Lenné, M. G., Stanton, N. A., Jenkins, D. P., \& Walker, G. H. (2010). Managing error on the open road: The contribution of human error models and methods. Safety Science, 48(10), 1225-1235.

Salmon, P. M., McClure, R., \& Stanton, N. A. (2012). Road transport in drift? Applying contemporary systems thinking to road safety. Safety Science, 50(9), 1829-1838. 
Salmon, P. M., Walker, G. H., M. Read, G. J., Goode, N., \& Stanton, N. A. (2017). Fitting methods to paradigms: are ergonomics methods fit for systems thinking? Ergonomics, 60(2), 194-205.

Sawyer, B.D., Finomore, V.S., Calvo, A.A., Hancock, P.A., (2014). Google glass a driver distraction cause or cure? Human Factors: The Journal of the Human Factors and Ergonomics Society. 56 (7), 555-573.

Schömig, N., \& Metz, B. (2013). Three levels of situation awareness in driving with secondary tasks. Safety Science, 56, 44-51.

Shinar, D., Tractinsky, N., \& Compton, R. (2005). Effects of practice, age, and task demands, on interference from a phone task while driving. Accident Analysis \& Prevention, 37(2), 315-326.

Simon, F., \& Corbett, C. (1996). Road traffic offending, stress, age, and accident history among male and female drivers. Ergonomics, 39(5), 757-780.

Stanton, N. A., \& Salmon, P. M. (2009). Human error taxonomies applied to driving: A generic driver error taxonomy and its implications for intelligent transport systems. Safety Science, 47(2), 227-237.

Summala, H., Lamble, D., \& Laakso, M. (1998). Driving experience and perception of the lead car's braking when looking at in-car targets. Accident Analysis \& Prevention, 30(4), 401-407.

Terry, H. R., Charlton, S. G., \& Perrone, J. A. (2008). The role of looming and attention capture in drivers' braking responses. Accident Analysis \& Prevention, 40(4), 1375-1382.

THINK! (2017) Mobile Phones. http://think.direct.gov.uk/mobile-phones.html. Accessed 20/05/2017.

Theeuwes, (2004). Top-down search strategies cannot override attentional capture. Psychonomic Bulletin \& Review 11, 65-70.

Tingvall, C., Ekstein, L., Hammer, M. (2009) Government and industry perspectives on driver distraction. In M.A. Regan, J.D. Lee, K.L. Young (Eds.), Driver distraction: Theory, Effects and Mitigation, CRC Press. Florida, USA.

Tivesten, E., \& Dozza, M. (2015). Driving context influences drivers' decision to engage in visual-manual phone tasks: Evidence from a naturalistic driving study. Journal of Safety Research, 53, 87-96.

Tonetto, L. M., \& Desmet, P. M. (2016). Why we love or hate our cars: A qualitative approach to the development of a quantitative user experience survey. Applied Ergonomics, 56, 68-74.

Tsimhoni, O., Smith, D., Green, P., (2004). Address entry while driving: speech recognition versus a touch-screen keyboard. Human Factors: Journal of Human Factors Ergonomics Society. 46 (4), 600-610.

Walker, G. H., Stanton, N. A., \& Young, M. S. (2001). Where is computing driving cars? International Journal of Human-Computer Interaction, 13(2), 203-229.

Walker, G. H., Stanton, N. A., \& Chowdhury, I. (2013). Self-Explaining Roads and situation awareness. Safety Science, 56, 18-28.

Walsh, S.P., White, K.M., Hyde, M.K. \& Watson, B.C. (2008) Dialling and Driving: Factors Influencing Intentions to Use a Mobile Phone While Driving. Accident Analysis and Prevention 40(6) 1893-1900.

Welsh, E. (2002). Dealing with data: Using NVivo in the qualitative data analysis process. In Forum Qualitative Sozialforschung/Forum: Qualitative Social Research 3(2).

Wickens, C. D. (2002). Multiple resources and performance prediction. Theoretical Issues in Ergonomics Science, 3(2), 159-177.

Wierwille, W. W. (1993). Demands on driver resources associated with introducing advanced technology into the vehicle. Transportation Research Part C: Emerging Technologies, 1(2), 133-142. 
World Health Organisation (2004). World Report on Road Traffic Injury Prevention. World Health Organisation Report. http://apps.who.int/iris/bitstream/10665/42871/1/9241562609.pdf Accessed 01/08/2017.

Young, K.L., \& Regan, M. (2007). Driver distraction: A review of the literature. In: I.J. Faulks, M. Regan, M. Stevenson, J. Brown, A. Porter \& J.D. Irwin (Eds.). Distracted driving. Sydney, NSW: Australasian College of Road Safety. pp.379405.

Young, K.L., Regan, M.A., \& Lee, J.D (2008). Factors moderating the impact of distraction on driving performance and safety. In: Young, K., Lee, J. D., \& Regan, M. A. (Eds.). (2008). Driver Distraction: Theory, Effects, and Mitigation. CRC Press.

Young, K. L., \& Lenné, M. G. (2010). Driver engagement in distracting activities and the strategies used to minimise risk. Safety Science, 48(3), 326-332

Young, K. L., Mitsopoulos-Rubens, E., Rudin-Brown, C. M., \& Lenné, M. G. (2012). The effects of using a portable music player on simulated driving performance and task-sharing strategies. Applied Ergonomics, 43(4), 738-746.

Young, K. L., Salmon, P. M., \& Cornelissen, M. (2013). Missing links? The effects of distraction on driver situation awareness. Safety Science, 56, 36-43.

Young, K.L., \& Salmon, P.M., (2015). Sharing the responsibility for driver distraction across road transport systems: a systems approach to the management of distracted driving. Accident Analysis and Prevention. 74, 350-359.

Young, M. S., Birrell, S. A., \& Stanton, N. A. (2011). Safe driving in a green world: A review of driver performance benchmarks and technologies to support 'smart'driving. Applied Ergonomics, 42(4), 533-539.

Zhou, R., Wu, C., Rau, P. L. P., \& Zhang, W. (2009). Young driving learners' intention to use a handheld or hands-free mobile phone when driving. Transportation Research Part F: Traffic Psychology and Behaviour, 12(3), 208-217.

Zhou, R., Rau, P. L. P., Zhang, W., \& Zhuang, D. (2012). Mobile phone use while driving: predicting drivers' answering intentions and compensatory decisions. Safety Science, 50(1), 138-149. 
Online Appendix. Thematic framework of the causal factors relating to the factors that influence their likelihood of engaging with technological tasks while driving. The framework is sub-diving into the systemic level; driver, infrastructure, task and context for ease of presentation.

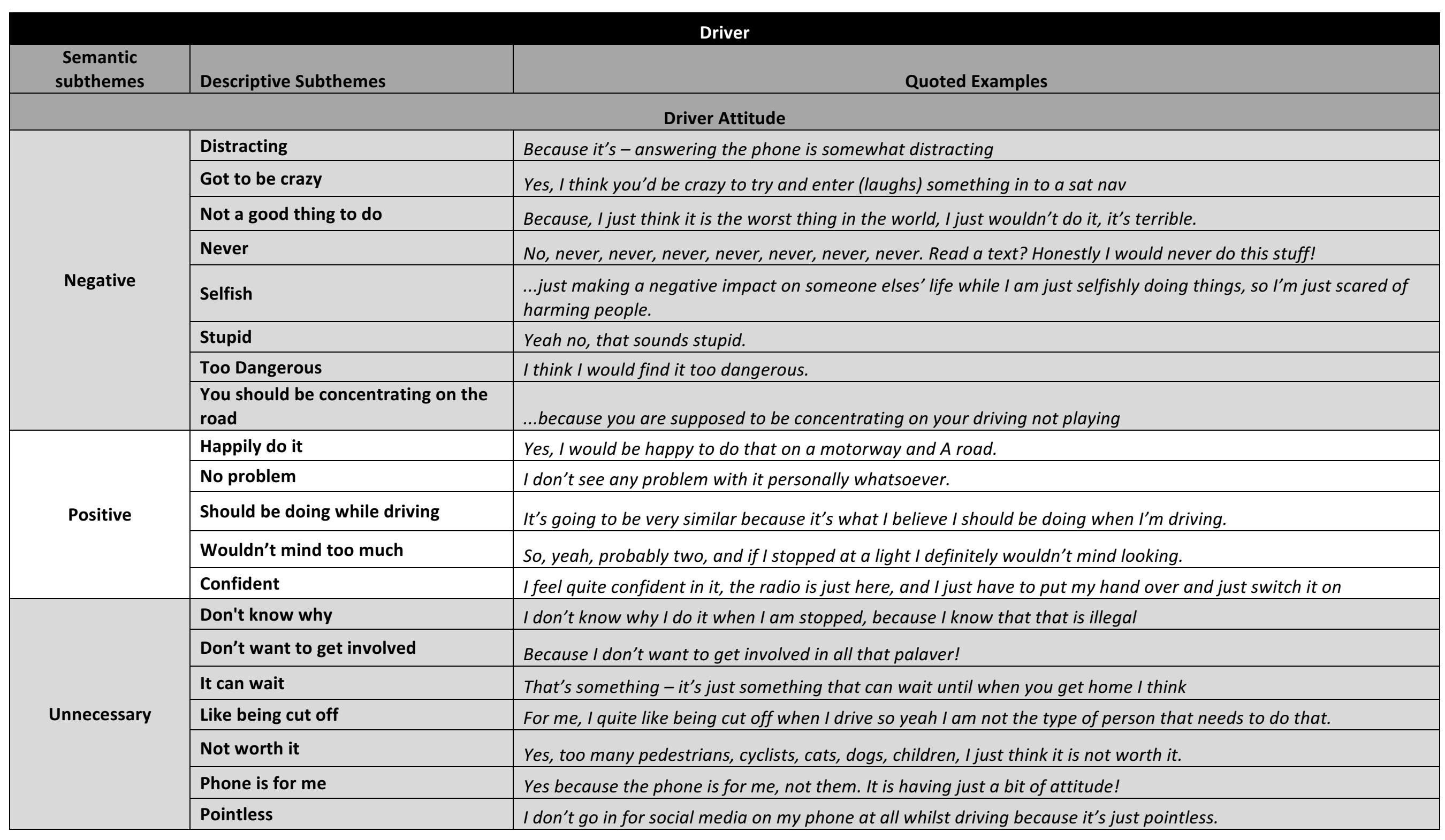




\section{Driver}

\begin{tabular}{|c|c|c|}
\hline $\begin{array}{c}\text { Semantic } \\
\text { subthemes }\end{array}$ & Descriptive Subthemes & Quoted Examples \\
\hline \multirow{8}{*}{$\begin{array}{l}\text { Influence of } \\
\text { others }\end{array}$} & If something happened & the shame if you did something bad, that everyone would think you are so stupid. \\
\hline & Negative of others & $\begin{array}{l}\text { I've seen people taking movies of themselves driving and I think, "How can you be doing that? Because you're looking at } \\
\text { your phone, you're not looking at the road at all, what are you doing?" }\end{array}$ \\
\hline & No one else suffers & $\begin{array}{l}\text { I'll wait until I feel kind of like l'm in a comfortable... like there's not too much going on around me so that if anything } \\
\text { does happen, the only one that's going to suffer is me, not anyone else. }\end{array}$ \\
\hline & Joining in & Yeah, yeah. I sort of joined a craze for a little bit. \\
\hline & Others seeing you & Almost some of it is the public shame, the shame if you did something bad, that everyone would think you are so stupid. \\
\hline & $\begin{array}{l}\text { Passenger interacts with } \\
\text { technology }\end{array}$ & $\begin{array}{l}\text { I look at it obviously to drive, but I have noticed that when I have people in the car they look at it because they can also } \\
\text { figure out where they are from their world. }\end{array}$ \\
\hline & Social peer pressure & Well the social peer pressure and some people don't think it's a very good thing to do and have told me so \\
\hline & Stories of accidents & My friend's mother got killed by someone being distracted, so this is really important to me. \\
\hline \multirow{12}{*}{ Tendency } & Can't say I wouldn't & I can't say I've never done it in my life \\
\hline & Do all the time & So, I do that all the time. I'd say pretty much. \\
\hline & Done before & I have been known to do that \\
\hline & Don't do it anymore & No. I used to check my emails a few years ago while I was working for another company \\
\hline & Don't like doing it & Yes, so on a motorway I don't like doing it but I would do it \\
\hline & Don't tend to & Okay, I have used my phone as a sat nav in the past; I tend not to. \\
\hline & Hate to say it & Well I hate to say it, but I have done this. \\
\hline & Hope they wouldn't & I would like to think I wouldn't take a selfie then that would be where I would be most likely to. \\
\hline & I've pulled over & Nowhere, I just wouldn't do it; l'd pull over and then do it pulled over. \\
\hline & Wouldn't think twice & I wouldn't think twice about verbal communication on either of those. \\
\hline & More than I would like & But I would probably actually monitor a sat nav higher than I would want to admit on that \\
\hline & Not a habit & Interesting; again, I'm not in a habit of doing it \\
\hline
\end{tabular}




\begin{tabular}{|l|c|l|}
\hline & Not done before & Yes I don't know why, I am just imagining myself doing it and I instinctively just wouldn't have done it. \\
\cline { 2 - 3 } & Try not to & I really try not to use my phone at all when I'm driving \\
\hline
\end{tabular}

\begin{tabular}{|c|c|c|}
\hline \multicolumn{3}{|r|}{ Driver } \\
\hline $\begin{array}{l}\text { Semantic } \\
\text { subthemes }\end{array}$ & Descriptive Subthemes & Quoted Examples \\
\hline \multirow{15}{*}{$\begin{array}{l}\text { View of } \\
\text { self/behaviour }\end{array}$} & Anxious & $\begin{array}{l}\text { I find it very difficult to not drive without music because I get quite anxious when I'm on the road, so I use it as a calming } \\
\text { mechanism. }\end{array}$ \\
\hline & Ashamed & I have done that on a motorway I'm ashamed to say \\
\hline & bad at multi-tasking & I just wouldn't be able to multi-task in that way. \\
\hline & Didn't think & Because I didn't really think through, I just did it. \\
\hline & Guilty & Changing a song/audio track, that's something I'm very guilty of a lot. \\
\hline & Lack of technological skill & Yes, maybe it is my lack of technology skills and my fat fingers, \\
\hline & Naughty & if I am stopped I generally am a little bit more naughty. \\
\hline & Poor sense of direction & I've got a poor sense of direction, so I use sat-navs an awful lot. \\
\hline & Scary & Answer a phone call. Yeah. I do which is actually slightly scary \\
\hline & Sneaky & then I probably would take a sneaky look at it \\
\hline & Stupid & Just stupid thinking back to it now but we used to, on the way to and back from work \\
\hline & Terrible driver & I am a terrible driver. \\
\hline & Too clumsy & So like, I always mistype stuff or like I hold my phone sometimes and because it's too big I drop it. \\
\hline & Too old & No. I am just one of the - I am probably a different generation, I am too old! \\
\hline & Unwise & It's unwise really \\
\hline
\end{tabular}




\begin{tabular}{|c|c|c|}
\hline $\begin{array}{l}\text { Semantic subthemes } \\
\text { themes }\end{array}$ & Descriptive Subthemes & Quoted Examples \\
\hline \multirow{5}{*}{$\begin{array}{l}\text { Perceptions of } \\
\text { surrounding } \\
\text { environment }\end{array}$} & Busyness & Because a major road, there's - I just feel like there's a lot more going on, on a major road. \\
\hline & Perceived risk & I am more likely to do it if it is on a motor way where I would say the risks are somewhat less, but it is rare \\
\hline & Familiarity & apart from I have to say navigating a junction, especially in an unfamiliar town or parking \\
\hline & Required attention & And maybe less there, very very unlikely for these roads and junctions, it would require a lot more concentration. \\
\hline & Other road users & $\begin{array}{l}\text { I think so, maybe when it wouldn't would be residential and urban roads where you have got to navigate traffic } \\
\text { calming, you know whatever it might be, someone crossing. }\end{array}$ \\
\hline \multirow{12}{*}{ Road Layout } & Corners & $\begin{array}{l}\text { Rural roads make me nervous because you just don't know what is going to be around the corner, they make me } \\
\text { nervous. }\end{array}$ \\
\hline & Opportunity to stop & $\begin{array}{l}\text { On A roads, urban roads, rural roads and residential roads you can't so much and as I said, the opportunity to stop } \\
\text { and actually find something is more convenient }\end{array}$ \\
\hline & Straight line & the motorway is straighter so you can monitor your environment and predict - well maybe predict it a bit better. \\
\hline & Turnings & $\begin{array}{l}\text { On an urban road l'd probably say that I'd monitor a route more closely because you're navigating by road names } \\
\text { and small turnings which can come up quicker and the whole- }\end{array}$ \\
\hline & Complicated & urban roads, because these are the complicated parts of the journey often aren't they? \\
\hline & Road environment & $\begin{array}{l}\text { sometime you can along these roads there aren't always great road markings and then, in the picture there you } \\
\text { have got high trees and that kind of things, }\end{array}$ \\
\hline & $\begin{array}{l}\text { Traffic moving in same } \\
\text { direction }\end{array}$ & yeah I would do that because to me a motor, once you are on it, it is all moving in the same direction generally. \\
\hline & Consistent & $\begin{array}{l}\text { whereas when you are on a motorway, you are kind of on a route that is easier to follow. It is more consistent, the } \\
\text { route }\end{array}$ \\
\hline & Road information & and the information you're given on the road is actually relatively - it's in advance \\
\hline & Size & $\begin{array}{l}\text { Rural road probably, it depends how rural, if it a really really tiny road I probably don't answer it because it is quite } \\
\text { nice to be able to hear the road }\end{array}$ \\
\hline & Lanes & I find music really distracting if I am parking or need to know which lane I need to be in a t a big roundabout. \\
\hline & Poor visibility & Yes, they've got very poor visibility \\
\hline
\end{tabular}




\section{Infrastructure}

\begin{tabular}{|c|c|c|}
\hline $\begin{array}{l}\text { Semantic subthemes } \\
\text { themes }\end{array}$ & Descriptive Subthemes & Quoted Examples \\
\hline \multirow{13}{*}{$\begin{array}{l}\text { Road related } \\
\text { behaviour }\end{array}$} & Speed & Yes, because we're driving so quickly down those roads \\
\hline & Performing a manoeuvre & I wouldn't do it when I'm manoeuvring through a junction, when I'm driving through a junction \\
\hline & $\begin{array}{l}\text { Break from looking at the } \\
\text { road }\end{array}$ & Just sick of staring at the road and so I would just have a quick look whilst I'm stopped at a traffic light. \\
\hline & Hand-brake on & junction it would probably be higher, again because of the whole handbrake on. \\
\hline & Not driving & I would wait until I'm stopped at a junction, instead of doing it when I'm actually driving. \\
\hline & Less driving involved & $\begin{array}{l}\text { I would say there is a higher chance on a motorway that I would read a text, because I would feel there was less } \\
\text { driving involved }\end{array}$ \\
\hline & Lane changing & because you do need to be very aware on a motorway about lane control and changing \\
\hline & Long journey & Okay, if you're on a motorway then yes I would because again it's a long bit of road, \\
\hline & Difficult driving task & Rural again, it's a more difficult driving task. \\
\hline & Experience & $\begin{array}{l}\text { I grew up in these rural roads and you really need to be on it, you can turn a corner and there is a horse, you really } \\
\text { need to be on it. }\end{array}$ \\
\hline & Nervous & you see I don't like rural road driving, it makes me nervous! \\
\hline & Commute to work & $\begin{array}{l}\text { I think because I am generally going slow, I am thinking that this is on my way to work which is generally } \\
\text { everything is stopped and you only move about 10ft and then it stops again }\end{array}$ \\
\hline & More decision & an urban road I think is more busy as well so I think the more sort of decisions you've got to make \\
\hline Illegality & Know I shouldn't & $\begin{array}{l}\text { I don't know why I do it when I am stopped, because I know that that is illegal still as well but something about } \\
\text { the engine running. But I do, if I am being honest. }\end{array}$ \\
\hline
\end{tabular}




\begin{tabular}{|c|c|c|}
\hline $\begin{array}{l}\text { Semantic subthemes } \\
\text { themes }\end{array}$ & Descriptive Subthemes & Quoted Examples \\
\hline \multirow{22}{*}{$\begin{array}{l}\text { Task-road } \\
\text { relationship }\end{array}$} & Slow down & But on a rural road l'd maybe slow down to do it, but it'd probably be just as likely. \\
\hline & Task quality & Rural roads, I suppose you've got the reception issue so you're less likely to have good reception \\
\hline & Utility & $\begin{array}{l}\text { I think I would need to use it more then, and even maybe in urban roads, because these are the complicated parts } \\
\text { of the journey often aren't they? }\end{array}$ \\
\hline & Wait for right conditions & I think I am likely to be very careful. I can see plenty way ahead there is nothing happening before I engage. \\
\hline & Limited completion & $\begin{array}{l}\text { Yeah it would be stilted, I would probably make the person on the phone aware, say hang on a minute but I would } \\
\text { probably sound not as engaged in the conversation. }\end{array}$ \\
\hline & Perceived ability & Junction I wouldn't because I think you just can't. \\
\hline & Not focused on the task & Because I think you'll be watching out and paying more attention to other things \\
\hline & Prepare in advance & Driving through a junction, actually - no I would have checked it before I went through. \\
\hline & Consequences & No I probably wouldn't because I wouldn't want to have to have the phone call afterwards, \\
\hline & Give it a go & A junction, yes stopped, l'd give it a go. \\
\hline & Good opportunity & $\begin{array}{l}\text { Maybe junction, if I stop at a junction I'd be a bit more likely because while I'm stationary I might take the } \\
\text { opportunity to just crank it up. I might do that. }\end{array}$ \\
\hline & Time stopped & Unless I was stopped for a period of time, if you're stopped, \\
\hline & Check nothing around you & $\begin{array}{l}\text { So entering a number on - entering a destination on the motorway, you'd just want to check to make sure that } \\
\text { there wasn't anything in front of you immediately or around you and then that buys you quite a lot of time on the } \\
\text { motorway }\end{array}$ \\
\hline & Ease of task & So, on a motorway, yes. I'd enter a number quite easily. \\
\hline & Just cruising & yeah, ok so changing climate controls I definitely would on the motorway, as long as you are just cruising along \\
\hline & More time & $\begin{array}{l}\text { Changing a radio station and a media system, motorway very likely for the reasons stated before; you have a lot } \\
\text { of time to just flick between the }\end{array}$ \\
\hline & Pull over & Residential I'd just definitely pull over. \\
\hline & Task length & Residential roads, less so. If was more than just a page that showed up at the start \\
\hline & Use alternative & Residential ... I probably would use a voice thing I think. \\
\hline & Cautious & Rural roads, more cautious but still highly likely, \\
\hline & Do it quickly & Rural roads, yeah, wouldn't mind reading one quickly. \\
\hline & Adjust task & urban road slightly less likely but probably just turn it off if I had to. \\
\hline
\end{tabular}


Semantic

subthemes

Ability to
complete

\begin{tabular}{|c|c|} 
task \\
\cline { 2 - 3 } & Pre-set options \\
\cline { 2 - 3 } & Couldn't do it \\
\hline I could do it \\
\hline $\begin{array}{c}\text { Cognitive processing } \\
\text { required }\end{array}$ \\
\cline { 2 - 3 }
\end{tabular}

\begin{tabular}{|l} 
Complexity \\
\hline
\end{tabular}

Desirability
Descriptive Subthemes

Adapt for driving

functionality

Consequences of initiating

Familiarity

Concentration required

Difficulty of task

\begin{tabular}{|c|}
\hline Difficulty of task \\
\hline Ease of task
\end{tabular}

Phone unlock

Effort

No alternative

Preference for alternative

Reliability

Technology quality

Trust

Use outside car Utility

\section{Quoted Examples}

I would probably filter calls more aggressively when I'm driving than I would -

No I probably wouldn't because I wouldn't want to have to have the phone call afterwards,

So certainly at least in my car, I don't have to look at the climate control system to change - because l've had the car for ages, I know where the switches are

if I was manoeuvring I would recognise the text has come through but I wouldn't read it to the extent that I would have taken it in, so I would glance over.

it's basically, this one is pre-set channels on the radio and pre-set channels and I only have to touch one button.

Um, because I can't drive and enter a destination at the same time because I would probably kill myself

if I can find a number from an address book, I can press a button to answer a call on the motorway.

Because you are not simply taking your eyes off the road to look, at the radio or the heating or something. Its reading something and then processing that.

I think ultimately I am going to be happy to do them on all of them, it doesn't really require much attention being taken away from the driving.

Just because it's a bit more fiddly

just because if you're clicking the air conditioning button or changing the radio station or whatever, all of those you can do fairly easily

Because if you have to unlock the phone screen or whatever etc., it is not as simple - well it is quite distracting Exactly, yes. It's exceptionally lazy; it really is an exercise in laziness. So yes again I would be very likely to do that.

On phone. Erm ... yes, I have had to actually, when my normal system's gone ka-blink, I've had to

So finding a number is probably nil for me because I would use the voice activated command, so I don't have to look away which is quite good.

If I have the phone you know on my face I would make a call usually only with the headset usually because it is more reliable.

Yes, it would probably be quite high. I don't like these systems because they never work

So that one would come down to trust. If I could trust that it would recognise my voice then I would do it all the time.

I don't really use my phone very much anyway so it's never been something that I have felt I have needed.

I've got a poor sense of direction, so I use sat navs an awful lot. 


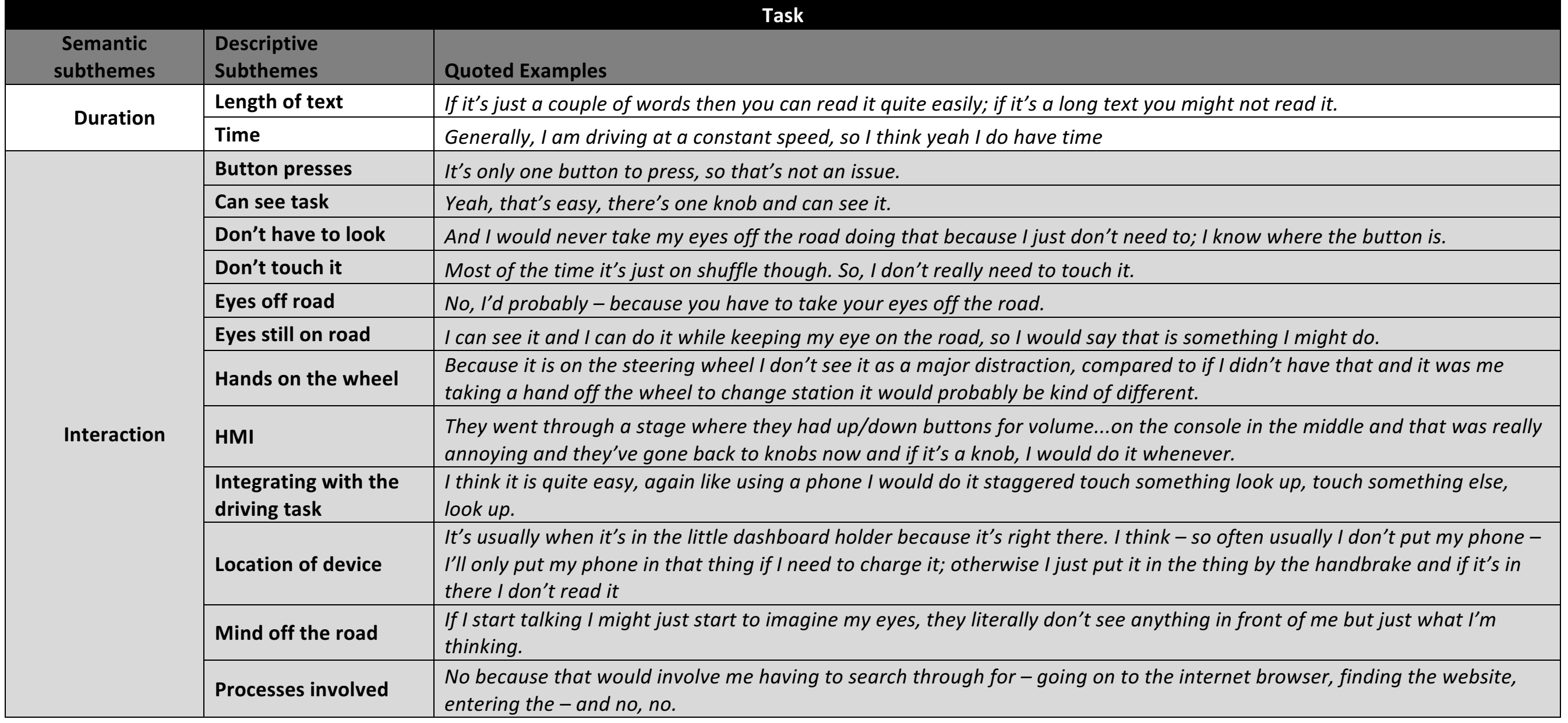




\begin{tabular}{|l|l|l|}
\hline $\begin{array}{l}\text { Semantic } \\
\text { subthemes }\end{array}$ & $\begin{array}{l}\text { Descriptive } \\
\text { Subthemes }\end{array}$ & Quoted Examples \\
\hline \multirow{5}{*}{$\begin{array}{l}\text { Engagement } \\
\text { regulation }\end{array}$} & Car doesn't allow it & Navigation? Whilst driving on a motorway! Well my car doesn't let me do it, for one thing. \\
\cline { 2 - 3 } & Conscious Decision & $\begin{array}{l}\text { I would probably look to see who it was and then I would make a decision if I was going to pull over and phone those } \\
\text { people back or just ignore it }\end{array}$ \\
\cline { 2 - 3 } & Curiosity & $\begin{array}{l}\text { if I'm expecting to meet someone, if I was going to do something and it was on the seat or something, I would think, "Oh," } \\
\text { your curiosity would be like, "Oh, I wonder who that's from? }\end{array}$ \\
\cline { 2 - 3 } & Do when not driving & So I will always figure out what I'm going to listen to and set it going before I leave. \\
\cline { 2 - 3 } & Don't use device/task & No. Oh sorry it has, it has got hands free technology, but I don't use it. \\
\cline { 2 - 3 } & Ignore & $\begin{array}{l}\text { Yes it is not audio because I find that too distracting, I get too involved if it is a story. } \\
\text { if anything were to happen on the phone, for example I hadn't got it connected to my Bluetooth and I got a call, I would } \\
\text { ignore it, which I've done on a number of occasions }\end{array}$ \\
\cline { 2 - 3 } & Reduce boredom & $\begin{array}{l}\text { I think it's just like driving's quite boring, isn't it, on the whole, so you tend to ... a phone's quite an easy thing to distract } \\
\text { you or just sort of get distracted, but like, you know, take away from all the boredom really. }\end{array}$ \\
\cline { 2 - 3 } & Response time & $\begin{array}{l}\text { Yes, so across all of them I would think it would all be context driven, whether I accept the call, if I think I could actually } \\
\text { press the button to accept the call quickly enough. }\end{array}$ \\
\cline { 2 - 3 } & "Reading a text", you see I would read a text just because of the nature of the fact that it flashes up on your phone. \\
\hline
\end{tabular}




\begin{tabular}{|c|c|c|}
\hline Semantic subthemes & $\begin{array}{l}\text { Descriptive } \\
\text { Subthemes }\end{array}$ & Quoted Examples \\
\hline \multirow{4}{*}{ Journey Context } & Familiarity & $\begin{array}{l}\text { I am now wondering if I am in a strange city, I would be less likely to mess around because I don't know where I am } \\
\text { going. }\end{array}$ \\
\hline & Journey length & So, it is who, again length of journey, if I am going to stop soon I probably wouldn't, But I would say I was driving. \\
\hline & journey type & Check your email. Yeah, I do, yeah. On my way home from work. \\
\hline & Time of day or night & $\begin{array}{l}\text { even when you're on a motorway, if my phone went off and it's dark, then I don't like to look at it just because then your } \\
\text { face is all lit up and someone else would know that you were looking at a phone and holding it. }\end{array}$ \\
\hline \multirow{4}{*}{ Road context } & Across all road types & So that is always, I would always do that, so across all road types. \\
\hline & $\begin{array}{c}\text { Busy-ness } \\
\text { environment }\end{array}$ & I think it would be situational dependent, just how busy is it? I think ... it would depend I think. \\
\hline & $\begin{array}{l}\text { Concentration } \\
\text { required from driving }\end{array}$ & And also I wasn't so busy thinking about the driving that I realised that I couldn't actually speak to the person. \\
\hline & $\begin{array}{c}\text { Feels } \\
\text { safe/comfortable }\end{array}$ & so again, it would be on whether I felt it was safe or not. \\
\hline \multirow{6}{*}{ Task Context } & Urgency/Importance & $\begin{array}{l}\text { It's stuff when I actually feel like I need to send a message quickly, so if I've agreed to come home at a certain time and } \\
\text { I'm running late for instance }\end{array}$ \\
\hline & Expecting something & $\begin{array}{l}\text { I don't like doing it, but then if you're expecting a call or ... And I mean I think if it was a call I'm expecting I would } \\
\text { probably answer it }\end{array}$ \\
\hline & Necessity & If I needed to I would, but I don't do it that often. \\
\hline & Required info to hand & there's a chance I would have a go at putting in the - and I had the postcode to hand, there's a chance I would do it. \\
\hline & In a hurry & If I was on a motorway going straight and I really needed to be somewhere, I was in a hurry, there's a chance \\
\hline & $\begin{array}{l}\text { Who they are } \\
\text { communicating with }\end{array}$ & $\begin{array}{l}\text { So, answer the call, I am actually quite unlikely to answer actually it would depend on who it was. If it is my boss then } \\
\text { that is different so it depends }\end{array}$ \\
\hline
\end{tabular}


